\title{
Belgeo
}

Revue belge de géographie

\section{Les équipements culturels de la vallée de l'Emscher (Ruhr, Allemagne) : de la régénération urbaine au développement d'une économie culturelle et créative}

Cultural facilities in the Emscher Valley (Ruhr, Germany): from urban

regeneration to the development of a cultural and creative economy

\section{Bruno Lusso}

\section{(2)enEdition \\ Journals}

Édition électronique

URL : http://journals.openedition.org/belgeo/13358

DOI : 10.4000/belgeo.13358

ISSN : 2294-9135

\section{Éditeur :}

National Committee of Geography of Belgium, Société Royale Belge de Géographie

\section{Référence électronique}

Bruno Lusso, « Les équipements culturels de la vallée de l'Emscher (Ruhr, Allemagne) : de la régénération urbaine au développement d'une économie culturelle et créative », Belgeo [En ligne], 3 | 2014, mis en ligne le 19 décembre 2014, consulté le 30 avril 2019. URL : http:// journals.openedition.org/belgeo/13358; DOI : 10.4000/belgeo.13358

Ce document a été généré automatiquement le 30 avril 2019

Belgeo est mis à disposition selon les termes de la licence Creative Commons Attribution 4.0 International. 


\title{
Les équipements culturels de la vallée de l'Emscher (Ruhr, Allemagne) : de la régénération urbaine au développement d'une économie culturelle et créative
}

\author{
Cultural facilities in the Emscher Valley (Ruhr, Germany): from urban \\ regeneration to the development of a cultural and creative economy
}

Bruno Lusso

\section{Introduction}

1 Cet article a pour objectif d'analyser les retombées de l'implantation d'équipements culturels dans le bassin minier de la Ruhr, et plus précisément dans la vallée de l'Emscher. Longtemps considérés comme un luxe subordonné à une croissance économique forte (Lusso, 2008), les investissements dans le domaine de la culture sont devenus à partir des années 1990 un outil de développement territorial. Face à l'essor d'une économie devenue majoritairement tertiaire (Voase, 1997) et fondée sur la connaissance (Lundvall et Johnson, 1994), de nombreux territoires ont fait le choix de mettre en avant l'originalité de leurs ressources culturelles et créatives pour continuer à être attractifs (Camagni, Maillat et Matteaccioli, 2004). La culture sert désormais de levier à nombre de projets de requalification urbaine (Andres et Ambrosino, 2008). Considérée comme motrice dans les processus de transformation physique, économique et sociale des espaces déprimés, la régénération culturelle (Bianchini et Parkinson, 1993) s'est imposée dans l'esprit des pouvoirs publics comme une des stratégies de développement urbain les plus efficaces, notamment sur les friches et anciens quartiers industriels, dans une optique de redynamisation territoriale et de marketing urbain (Ingallina et Park, 2005). Dans ce cadre, les équipements culturels que l'on peut définir comme des lieux de consommation 
de biens et de services culturels (musées, galeries, salles de spectacles, bibliothèques...) où se mêlent aussi des dimensions d'éducation et de loisirs (Lucchini, 1997), jouent un rôle primordial.

2 Ces «projets culturels porte-drapeaux » ou flagship cultural projects (Bianchini, Dawson et Evans, 1992 ; Voase, 1997 ; Communian, 2014) sont lancés dans l'optique d'affirmer les villes sur la scène internationale (Pfirsch et Reitel, 2014), notamment celles qui, marquées par la crise économique et sociale, cherchent un nouveau destin (Ingallina et Park, 2005). Cette politique est pourtant déjà assez ancienne et trouve notamment ses origines dans la réussite économique des Festival Market Places (Gravari-Barbas, 1998), qui sont de grands projets de reconquête des fronts d'eau délaissés dans les villes nord-américaines menés dès les années 1960 pour y accueillir des activités commerciales, touristiques ou ludorécréatives. À partir des années 1980, les villes anglo-saxonnes commencent à investir massivement dans la construction d'équipements culturels structurants (Voase, 1997), comme le montrent les exemples des métropoles états-uniennes (Grodach, 2010) ou des villes anglaises des Midlands (Wilkinson, 1992 ; Landry, Greene, Matarasso et Bianchini, 1996 ; Landry, 2000). Mais c'est avec le succès du musée Guggenheim implanté à partir 1997 dans la cité sidérurgique de Bilbao que le mouvement s'accélère. La médiatisation de l'antenne du musée d'art moderne et contemporain new-yorkais sur le site d'une ancienne aciérie, ainsi que le projet architectural développé par Frank Gehry, ont stimulé l'économie touristique locale et la poursuite d'un ambitieux projet urbain, contribuant au renouveau de la ville (Gomez et Gonzales, 2001; Masboungi, 2001). Les flagship cultural projects se multiplient dans les villes industrielles en crise à l'image de l'Imperial War Museum North à Manchester ou du Musée des Arts Contemporains à Mons (Lusso, 2009). La France n'échappe pas à la dynamique avec les projets d'antenne du Centre Pompidou à Metz (Boquet, 2014) et du Louvre à Lens (Baudelle et Krauss, 2014).

3 La particularité de la Ruhr, région industrielle localisée à l'ouest de l'Allemagne et confrontée dès les années 1960 au recul de son activité charbonnière et sidérurgique, est d'avoir développé à l'échelle de la vallée de l'Emscher, un périmètre de 17 communes comptant une population de 2,5 millions d'habitants, une ambitieuse politique de reconversion qui passe par l'implantation de grands équipements culturels. La Ruhr (et plus précisément la vallée de l'Emscher) est une vaste conurbation constituée de noyaux urbains de taille similaire et ne disposant pas d'une importante mixité fonctionnelle et de ville-capitale (Faust, 1999 ; Boldt et Gelhar, 2008). De ce fait, au-delà du renversement de l'image territoriale, le développement de flagship cultural projects dans la vallée de l'Emscher concourt à la diversification fonctionnelle d'une conurbation organisée autour de la mono-industrie. 


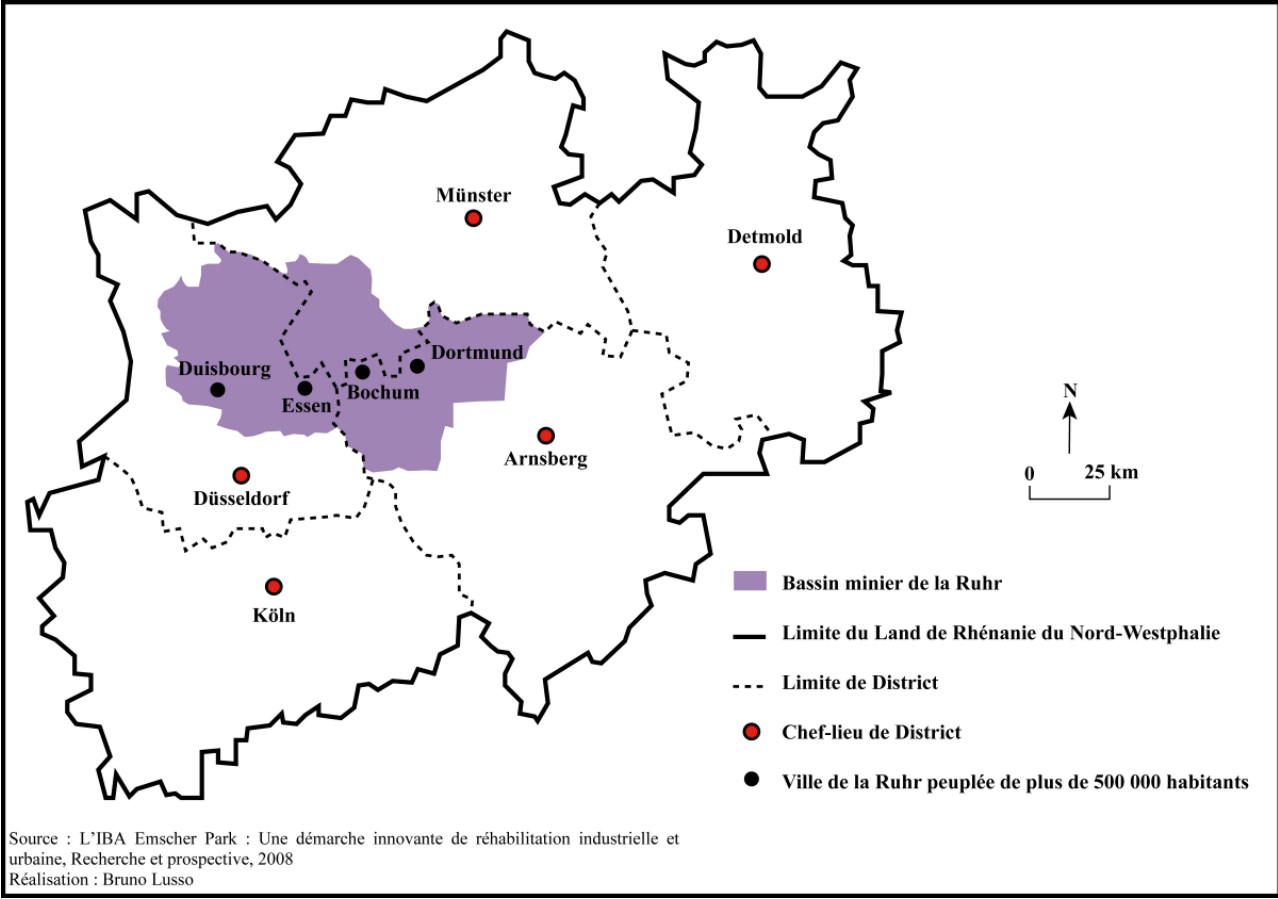

Les modalités de reconversion économique et de recyclage des friches industrielles à l'échelle du bassin minier de la Ruhr est une question qui a fait l'objet de recherches approfondies en géographie et aménagement (Holz, 1988 ; Joly, 2001 ; Kunzmann, 1996 ; Ganser, 2001). Ces travaux ont souligné les caractéristiques institutionnelles du territoire, les dispositifs d'aménagement, leur financement, les modalités de reconversion paysagère et économique des sites industriels, ainsi que les résultats de ces politiques en matière de développement territorial. L'objectif de cet article est d'analyser les retombées des équipements culturels créés dans le cadre des politiques de reconversion menées à l'échelle de la vallée de l'Emscher. Pour ce faire, notre propos se divisera en trois parties :

- une présentation du cadre politique et des actions menant à la création d'un tissu d'équipements culturels très dense ;

- les retombées territoriales de ces équipements culturels ;

- les enjeux concernant la pérennisation de l'économie culturelle et créative régionale.

Afin de développer ces différentes thématiques, il a été nécessaire d'identifier dans un premier temps l'ensemble des équipements culturels implantés dans la Ruhr. Une liste non exhaustive a été établie à partir des annuaires téléphoniques et d'une géolocalisation grâce à Google Earth des sites culturels implantés sur des friches industrielles Ce travail préalable a permis d'élaborer un questionnaire envoyé à une dizaine d'équipements culturels de la vallée de l'Emscher. Celui-ci posait les questions de la réhabilitation de l'infrastructure, des publics accueillis, des activités mises en place par les structures, du budget et des modes de financement de l'institution. Cette connaissance des principales structures culturelles créées sur d'anciens sites industriels a été utile lors des entretiens semi-directifs réalisés auprès des collectivités territoriales (municipalités, Association régionale de la Ruhr) et de chercheurs allemands francophones. Ces entretiens avec différents acteurs ont permis de reconstituer une chronologie globale des politiques de reconversion menées dans la vallée de l'Emscher, ainsi que des mesures développées en 
faveur du recyclage des friches industrielles en équipements culturels. La lecture des plans d'aménagement et de la littérature portant sur les thématiques de reconversion développées dans la vallée de l'Emscher a complété ces informations.

\section{Politiques territoriales et modalités d'émergence des équipements culturels}

6 La vallée de l'Emscher fait partie d'une vaste conurbation minière considérée au début des années 1980 par nombre d'édiles et d'aménageurs comme étant en crise, physiquement dévastée et mal intégrée, notamment en raison de l'absence de structure capable de développer d'ambitieux projets urbains à une échelle plus large que celle des municipalités (Ganser, 2001). De ce fait, l'ambition d'implanter des équipements culturels sur d'anciennes friches industrielles revêt autant de la volonté de recoudre le tissu urbain, que de créer de nouvelles polarités ou de construire une ambition métropolitaine (Pfirsch et Reitel, 2014). Cette première partie vise donc à analyser les politiques d'aménagement qui ont conduit à la création d'un tissu dense d'équipements culturels.

\section{Les caractéristiques d'une région industrielle en crise}

7 La Ruhr, et plus précisément la vallée de l'Emscher, a pour caractéristique d'avoir connu un déclin industriel et économique accéléré après la Seconde Guerre mondiale. Les progrès du transport maritime mettent directement en concurrence la production charbonnière et industrielle peu compétitive de la Ruhr avec celle de pays comme les Etats-Unis, la Chine ou l'Australie. La région connaît dès la fin des années 1960 une récession de la production charbonnière qui devrait définitivement cesser en 2018. Face à ce processus inéluctable de désindustrialisation, les pouvoirs publics ont cherché à assurer le plus rapidement possible un redéploiement économique dans les secteurs tertiaire (services aux entreprises, formation, culture...), mais aussi industriel (implantation d'unités de fabrication dans le secteur des constructions mécaniques) (Schneider, 1991). Depuis les années 1970, la plus grande région industrielle et urbaine d'Allemagne, par le biais d'un important transfert de ressources budgétaires, a gardé non sans difficulté une base industrielle forte, notamment dans le domaine de la sidérurgie et a développé la filière automobile (usine Opel à Bochum qui a malgré tout fermé ses portes en 2014). Toutefois, le secteur tertiaire, en dépit de la création de structures de formation comme l'université de Bochum, se développe moins bien qu'ailleurs en Allemagne. En fait, dans une région dominée par de très grandes entreprises pendant longtemps peu concernées par la concurrence, le milieu entrepreneurial est demeuré clairement hostile à toute forme d'innovation (Ganser, 1996).

Les nouvelles activités n'ont pas réussi à compenser la forte hémorragie de l'emploi provoquée par ce vaste processus de désindustrialisation. La Ruhr, qui a perdu 200000 emplois entre 1961 et 1981, est marquée par un taux de chômage particulièrement élevé. $\mathrm{Au}$ début des années 1980, le chômage touche plus de 160000 personnes. Une telle situation explique la pauvreté de la région qui enregistre des recettes fiscales nettement inférieures à celles des villes rhénanes comme Cologne ou Düsseldorf. Les villes, pénalisées par la perte des taxes professionnelles, ont dû assurer le traitement social du chômage, ce qui a en grande partie bloqué leur capacité d'investir dans de nouvelles activités. A cela s'ajoute l'image répulsive du «pays noir»(Ganser, 1996). La Ruhr 
manque clairement de qualités urbaines et paysagères (Ganser, 2001). Cette région, qui ne compte pas de ville-capitale, s'est urbanisée par agglomérations greffées en peu de temps sur les noyaux villageois et autour d'une industrialisation qui s'est développée sans contrainte, colonisant tout l'espace et laissant aujourd'hui derrière elle des milliers d'hectares de friches. Cette situation est particulièrement dramatique dans la vallée de l'Emscher qui concentre un très grand nombre de sites industriels contaminés et qui est aussi traversée par la rivière la plus polluée d'Europe occidentale au début des années 1990. Cette image fortement dépréciée explique le solde migratoire négatif et le déclin démographique de la Ruhr : de 1955 à 1980, la population est passée de 6,2 à 5,4 millions d'habitants. Ainsi, tout l'enjeu des pouvoirs publics de la conurbation industrielle est de renverser l'image négative de leur territoire, en développant des stratégies urbaines innovantes dans lesquelles la culture a désormais une place de choix.

Dans la vallée de l'Emscher, les friches minières occupent de vastes surfaces - plusieurs dizaines d'hectares en moyenne - situées le plus souvent en périphérie des villes ou des centres urbains. Leur localisation, dans la continuité ou au sein même du tissu urbain, entraine généralement de véritables coupures urbaines qui constituent un frein au développement de ces conurbations industrielles. Dans l'attente d'un éventuel rachat ou d'une réhabilitation, les bâtiments sont sécurisés par des clôtures électriques ou surveillés par des gardiens. Laissées à l'abandon par leurs anciens propriétaires, ces friches industrielles se dégradent au fil des années créant ainsi une véritable pollution visuelle. Leur requalification devient pour les collectivités autant un objectif qu'un problème en raison de la nécessaire dépollution de ces sites marqués par des décennies d'activité industrielle. Deux possibilités s'offrent donc aux aménageurs :

- La première consiste en la démolition totale de la friche pour reconstituer un site vierge peu contraignant quant à son urbanisation future.

- La seconde vise la protection du patrimoine industriel et la réutilisation des bâtiments existants pour de nouvelles activités, solution qui pose cependant la question de la réadaptation du bâtiment à de nouveaux usages.

C'est finalement la deuxième option qui est largement privilégiée dans la vallée de l'Emscher. Les premières mesures de protection du patrimoine industriel apparaissent au début des années 1980 (Prossek, Schneider, Wessel, Wetterau et Wiktorin, 2009) et font suite à un ensemble de protestations émanant de la société civile. En 1969, un groupe d'artistes choqués par le projet de destruction du complexe minier Zollern II-IV à Dortmund, décide d'occuper la salle des machines pour en empêcher son démantèlement. Parmi eux, les photographes Bernd et Hilla Becher qui entament dès la fin des années 1970 un véritable travail d'entomologistes du patrimoine industriel (Becher et Becher, 1970 ; Becher et Becher, 1985). Ils constituent un catalogue précis d'images d'usines et d'infrastructures industrielles abandonnées contribuant ainsi à renverser la vision qu'ont les habitants, les décideurs politiques et les aménageurs de leurs paysages industriels. Désormais, mines, lavoirs, aciéries, cokeries et terrils revêtent aux yeux des populations un caractère identitaire (Soyez, 1999).

11 Disposant d'importantes prérogatives en matière d'aménagement du territoire (Bronny, Jansen et Wetterau, 2002), les municipalités mettent en place toute une série de mesures visant à protéger et à reconvertir ces sites industriels désaffectés. Le premier syndical intercommunal d'Allemagne, l'Association du district minier de la Ruhr (SVR, Siedlungsverband Ruhrkohlenbezirk) a été créé en 1920. Celui-ci a lancé dès 1951 un schéma de reconquête des friches industrielles complété à la fin des années 1960 par un 
programme de création d'équipements de loisirs. En 1979, le SVR devient une association de communes du bassin de la Ruhr (KVR, Kommunalverband Ruhrgebiet) qui assure, sans pour autant avoir une stratégie foncière propre, la protection de l'environnement, l'entretien des paysages, la reconquête des friches industrielles et la mise en place d'infrastructures de loisirs. Ainsi, dès les années 1980, la question du traitement ponctuel des friches minières, qui s'appuie sur la reconnaissance du patrimoine industriel et le développement de bases de loisirs, fait l'objet d'une stratégie régionale dotée de moyens d'action conséquents provenant notamment des villes et du Land de Rhénanie du NordWestphalie. La réhabilitation en 1977 des anciens ateliers ferroviaires de BochumDalhausen en un musée consacré aux chemins de fer ou la création en 1984 à Hamm du Maximilian Park, un jardin public implanté sur le site d'une mine et d'un lavoir désaffectés, témoigne de ces politiques.

\section{Le poids décisif de l'IBA Emscher Park}

La reconversion de l'ancien bassin minier de la Ruhr connaît un véritable coup d'accélérateur dans la seconde moitié des années 1980. En 1986 sont décidés la fermeture et le démantèlement du vaste complexe minier Zollverein constitué de douze puits et d'une cokerie. Face à ce projet, Karl Ganser, professeur de Géographie à l'Université Technique de Munich qui travaille au service d'Urbanisme du Land de Rhénanie du NordWestphalie, réussit à empêcher la démolition de l'ensemble considéré comme un véritable témoin de l'histoire culturelle de la région (Prossek, Schneider, Wessel, Wetterau et Wiktorin, 2009). Alors que les opérations de reconversion dans la Ruhr étaient jusque-là globalement ponctuelles, cet événement initie une évolution radicale. En effet, Charles Ganser et le Land de Rhénanie du Nord-Westphalie sont convaincus de la nécessité d'inscrire les différents projets de reconversion dans le cadre plus large d'un schéma de cohérence métropolitaine. En 1987, le Land accepte la création et le financement d'une Exposition Internationale d'Architecture (IBA, Internationale Bauausstellung). Concept développé dès les années 1920 en Allemagne, l'IBA cherche à réaliser à l'échelle d'un vaste territoire et sur un temps limité des projets urbains innovants et durables. Si le Land voit dans l'IBA la possibilité d'assurer la reconversion du bassin minier de la Ruhr, encore faut-il convaincre les villes, ainsi que les associations communales et régionales. Or, le projet d'IBA se heurte à une incompréhension quasiment générale de la part des acteurs locaux, et plus précisément des plus grandes villes qui ne voient pas l'intérêt de la démarche et de la possibilité d'une intervention à l'échelle intercommunale (Masboungi, 2000). Des villes comme Essen et Dortmund refusent même toute forme de partenariat. Ce sont finalement la participation active des plus petites villes à la démarche et la promesse du Land d'investir dans les projets de reconversion qui convainquent les plus grandes villes de s'inscrire dans la logique de l'IBA.

13 C'est en 1989 que le Land de Rhénanie du Nord-Westphalie lance pour une durée de dix ans l'IBA dans la vallée de l'Emscher. Cette opération médiatique vise, selon les mots de son directeur Charles Ganser, à attirer des architectes de renom et à susciter de grands projets innovants à partir de la réutilisation d'anciennes friches industrielles, dans l'espoir de provoquer une transformation structurelle de la région (Ganser, 1996). Rejetant l'idée de planification spatiale, l'IBA labellise et soutient uniquement des projets qui s'appuient sur la réutilisation des bâtiments existants, le patrimoine, l'écologie et la festivalisation de la culture. L'objectif de l'IBA est d'offrir un cadre permettant aux 
collectivités territoriales de réhabiliter les friches industrielles avec l'aide de paysagistes ou d'artistes. Il s'agit donc de donner un nouvel usage à ces espaces en favorisant la diversité des fonctions, mais aussi la reconstitution d'un paysage et d'un cadre de vie agréables. Afin d'endiguer la consommation de sites vierges dans une région densément peuplée, l'IBA renforce les procédures existantes qui imposent aux communes souhaitant urbaniser de nouveaux terrains de prouver qu'aucun autre foncier situé en zone déjà urbanisée n'est disponible. Cependant, la reconquête des friches pose la question de la décontamination des sites. Ainsi, dans le cas de coûts de décontamination trop élevés, l'IBA préfère ne pas utiliser les sols et attendre que la nature les retraite avec le temps. Cette stratégie vise donc à préparer d'abord le territoire pour le rendre ensuite attractif. Une telle approche suppose l'acceptation d'un impact territorial différé.

Figure 2. Les acteurs de l'IBA Emscher Park.

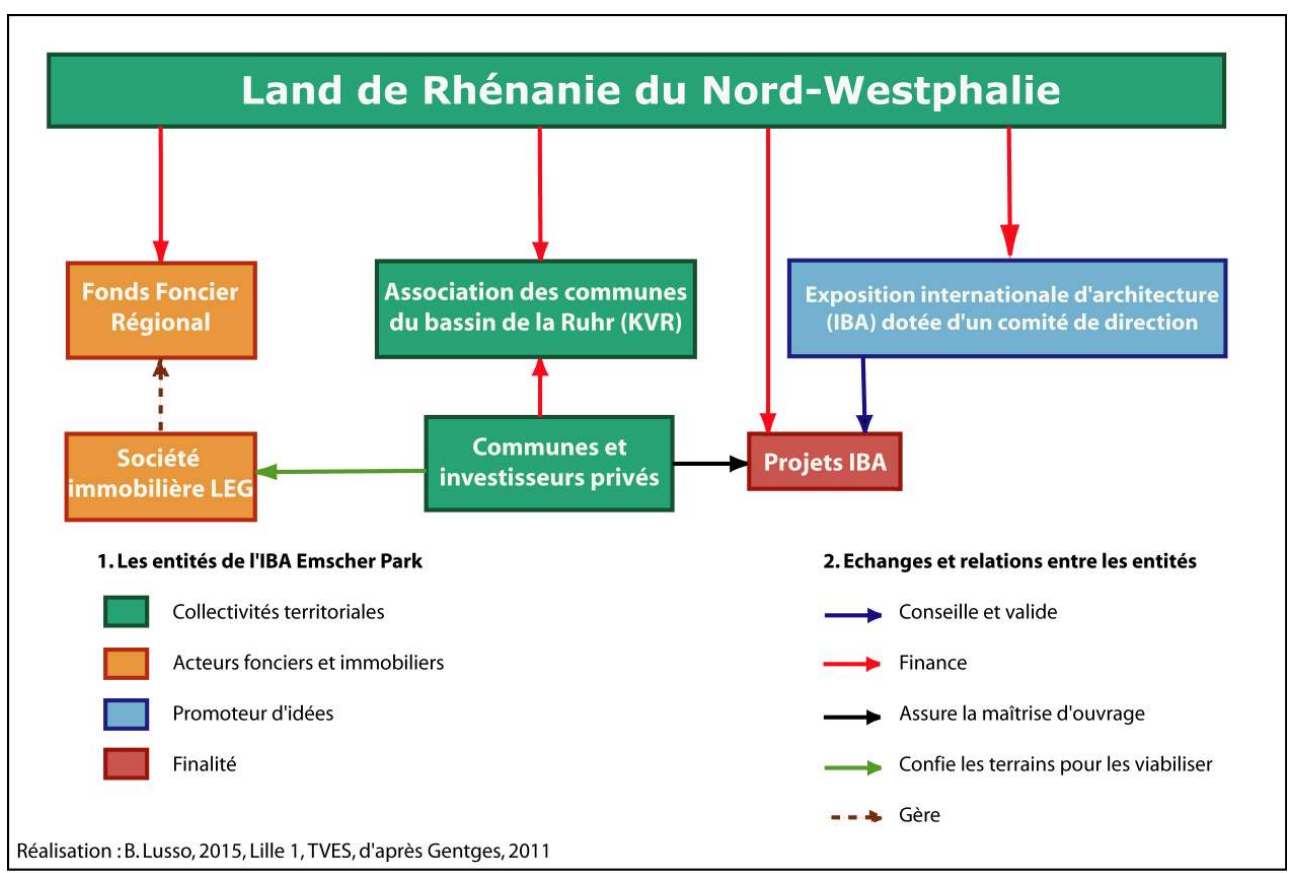

14 Pour concrétiser les principes développés par l'IBA, une société de droit privé appartenant conjointement à l'État et au Land de Rhénanie du Nord-Westphalie, l'IBA Emscher Park, est créée en 1989. Celle-ci prévoit pour la fin de l'année 1999 la réalisation de 120 projets d'aménagement (création d'une trame verte, restauration écologique du système fluvial de l'Emscher, implantation de parcs technologiques, réhabilitation, rénovation et construction de logements, préservation des friches industrielles pour des fonctions culturelles et artistiques), ainsi que l'organisation d'un bon nombre d'événements festifs dans le périmètre des 17 communes de la vallée de l'Emscher. Une SARL d'une durée de vie limitée à 10 ans, IBA Gmbh, est créée par le Land pour mettre en œuvre ce programme. L'IBA est plutôt un promoteur d'idées. L'initiative et la maitrise d'ouvrage des projets restent du ressort de la commune concernée ou de sociétés d'aménagement commanditées par la commune elle-même. Un comité associe des représentants du Land, des villes concernées, du monde économique, des syndicats, des associations et des architectes.

Pour assurer la réalisation de ces projets d'aménagement, le Fonds Foncier Régional ( Grundstücksfond) créé en 1980, met à disposition des financements publics destinés à la 
reconversion des friches industrielles. Sa vocation est de remettre dans le circuit économique des terrains hors marché du fait des coûts de décontamination qui leur sont souvent associés. L'objectif visé est double: réhabiliter un paysage et un tissu urbain détruits par l'industrialisation et répondre à la pénurie de foncier disponible dans une région densément peuplée. Grâce à une dotation de 100 millions de marks par an (environ 50 millions d'euros), le fonds est intervenu sur 160 terrains, soit une surface de 2500 hectares. $40 \%$ d'entre eux ont pu être revendus pour accueillir de nouvelles activités ou ont été reconvertis en espaces verts. La gestion du fonds est confiée depuis 1979 à la LEG (Landesentwicklungsgesellschaft), une société immobilière et d'aménagement de droit privé, dont le Land détient la majorité du capital. Cette société gère les biens fonciers et immobiliers, et assure les services d'aménagement, de maîtrise d'ouvrage et de développement.

À la fin de l'IBA, le Land de Rhénanie du Nord-Westphalie a mis en place une structure, Die Regionallen, permettant à d'autres territoires de bénéficier d'un dispositif similaire qui s'appuie désormais sur des projets d'une durée de deux ans et financièrement moins bien dotés. Dans le cadre de l'IBA, le rôle du KVR a été renforcé, notamment par le développement de nouvelles compétences culturelles et économiques, mais surtout grâce à la gestion du parc paysager de la vallée de l'Emscher. En 2004, le KVR est devenu l'Association régionale de la Ruhr (RVR, Regionalverband Ruhr) avec des prérogatives élargies en matière de planification spatiale. Ainsi, en 2007, une stratégie a été mise en place par les 35 villes de la Ruhr, soit une population totale de 4,8 millions d'habitants, pour réaliser environ 300 projets reposant sur le développement durable, l'identité et les qualités architecturales et paysagères. Le financement de ces projets Konzept Ruhr est assuré par le biais d'un partenariat entre les pouvoirs publics et des investisseurs privés. C'est le cas de l'ancienne mine Ewald fermée en 2001 qui a fait l'objet d'une reconversion menée par la ville de Herten en partenariat avec une société immobilière, RAG Montan Immobilien $\mathrm{GmbH}$, pour y accueillir un parc technologique, une zone logistique et des activités culturelles.

\section{Un tissu d'équipements culturels dense et équilibré}

17 Grâce à la coopération des acteurs et d'importants financements notamment durant l'IBA, le bilan des opérations de recyclage des friches minières menées dans la vallée de l'Emscher est particulièrement impressionnant. Ainsi, le parc paysager de la vallée de l'Emscher, d'une surface totale de $320 \mathrm{~km}^{2}$, a été constitué grâce à la réhabilitation de 93 sites différents. Les infrastructures industrielles ont été plus ou moins profondément réaménagées pour être adaptées à de nouveaux usages. De nombreux autres carreaux ont été partiellement préservés et reconvertis (Deshaies, 2007). D'autres ont été détruits. C'est le cas d'une immense aciérie de Gelsenkirchen entièrement démantelée - il ne reste que le bâtiment administratif - pour faire place au parc scientifique de Rheinelbe. La conservation des sites n'a donc pas été une politique systématique dans la vallée de l'Emscher. Il s'agit plutôt de garder quelques sites remarquables inscrits depuis 1999 dans le cadre de la Route de la culture industrielle (Route der Industriekultur). Autour des quatre grands sites emblématiques (gazomètre d'oberhausen, Landschaftspark de Duisbourg Nord, complexes miniers Zollern et Zollverein), la Route de la culture industrielle est composée de 52 sites industriels, dont seulement 11 sont strictement miniers. Ces sites qui constituent la Route de la culture industrielle, ont donc pour objectif, au-delà de la transmission de la mémoire, de réaffirmer l'identité industrielle de la Ruhr. Dans 
l'optique de connecter les sites régionaux avec d'autres localisés en France, en Belgique, en Pologne ou en Suède, le Land de Rhénanie du Nord-Westphalie a alors initié à partir de 2002 un projet de route européenne du patrimoine industriel qui s'appuie notamment sur un grand nombre d'équipements culturels.

Figure 3. Localisation des équipements culturels créés dans le cadre des politiques de reconversion de la vallée de l'Emscher.

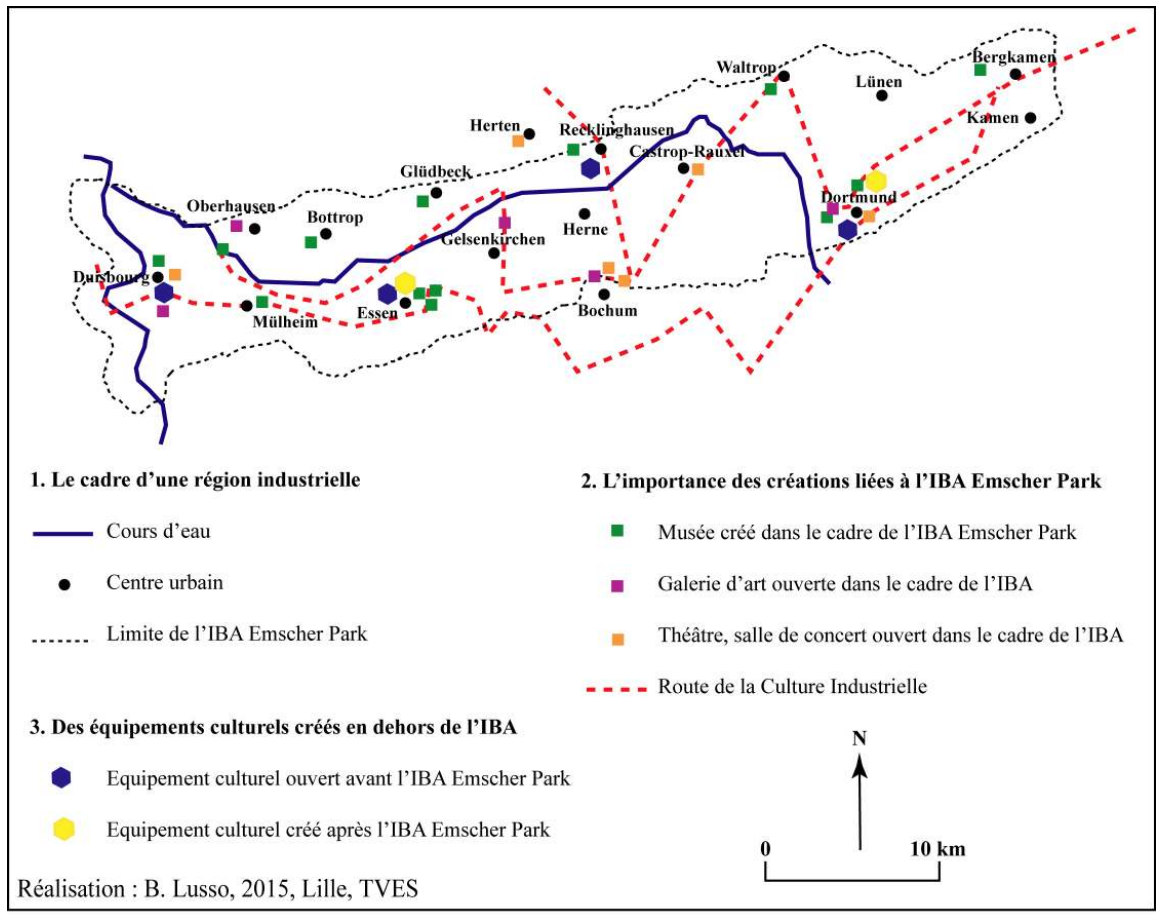

Déterminer un inventaire précis des équipements culturels dans une région densément peuplée est une une chose assez malaisée. Certains équipements récents et de très petite taille côtoient des institutions qui sont implantées depuis plusieurs décennies. La Route de la culture industrielle identifie à l'échelle de la vallée de l'Emscher un total de 43 équipements culturels et/ou pôles culturels, dont une vingtaine provient de l'IBA Emscher Park. Comme la vallée de l'Emscher dispose d'un riche patrimoine matériel et immatériel, il n'est pas étonnant de constater la prééminence des musées (une dizaine au total) qui investissent des ensembles miniers reconvertis et développent des thématiques de culture industrielle et scientifique. Les thématiques sont très diversifiées, de l'histoire minière (musées de la mine Zollverein à Essen, Zollern à Dortmund, Hannover à Bochum, Nachtigal à Witten) à l'énergie (musée de l'électricité dans un ancien transformateur de Recklinghausen), en passant par les technologies de l'eau (musée de l'eau dans un ancien château d'eau de Mülheim an der Ruhr) ou l'industrie ferroviaire (musée du chemin de fer de Bochum-Dalhausen sis dans un ancien entrepôt ferroviaire). Il faut dire que les thématiques retenues pour ces musées sont principalement axées sur les sciences et les technologies. Cette discipline muséale qui s'appuie en grande partie sur les effets spéciaux et l'interactivité, connaît depuis les années 1980 un succès grandissant auprès du public (Lusso, 2009). 
D'autres équipements culturels sont en fait des lieux de diffusion de la création artistique locale, quasiment exclusivement créés dans le cadre des opérations menées par l'IBA Emscher Park à une époque où les villes de la conurbation ne disposaient de quasiment aucun équipement culturel d'envergure. Ces structures culturelles peuvent être des salles de spectacle sises dans d'anciennes installations industrielles (Jahrhunderthalle de Bochum) ou en plein air (amphithéâtre de 800 places du terril Haniel à Bottrop/ Oberhausen), mais aussi des lieux de performances artistiques temporaires (gazomètre d'Oberhausen), et des espaces dédiés aux activités ludiques (parc d'attraction Maximilian Park à Hamm, Landshaftspark de Duisbourg proposant des activités sportives, mais aussi patrimoniales et/ou culturelles). Certains équipements culturels s'inscrivent dans le cadre de vastes complexes dédiés à la culture et à la création (Cité du design d'Essen comprenant un musée du design, un musée de la mine et un musée sur l'histoire industrielle de la Ruhr et un quartier créatif). Ces grosses structures côtoient des projets culturels d'envergure beaucoup plus locale et non moins nombreux comme l'illustre le cas du Kultur-Café installé dans l'ancienne mine Ickern à Castrop-Rauxel. S'il est clair que la diversité des équipements culturels désormais implantés dans la vallée de l'Emscher est digne d'une véritable métropole (Prossek, Schneider, Wessel, Wetterau, Wiktorin, 2009), nous pouvons néanmoins nous demander si cette densité n'est pas aussi synonyme de suréquipement culturel dans une région qui reste marquée par un taux de chômage élevé et donc par des difficultés pour les populations à financer des sorties culturelles globalement coûteuses.

En une quarantaine d'années, la vallée de l'Emscher a réussi à construire un vaste tissu d'équipements culturels qui doit surtout son existence aux actions menées dans le cadre de l'IBA Emscher Park (1989-1999). Si les coopérations entre les 17 communes de la vallée de l'Emscher ont été initialement très difficiles, le choix retenu par l'IBA de développer un volet culturel et patrimonial a facilité l'adhésion rapide des populations au projet, puis celle des collectivités territoriales. Au-delà de doter une ancienne conurbation industrielle de fonctions métropolitaines prestigieuses, la création d'équipements culturels dans la vallée de l'Emscher a contribué à unifier un territoire initialement très morcelé autour d'une même stratégie métropolitaine. Les projets KonzeptRuhr et Parc paysager Emscher 2010 illustrent clairement la nécessité pour les villes de la Ruhr de travailler de manière collégiale dans la construction de leur avenir métropolitain (Gentges, 2011). Pour autant, peut-on dire que les équipements culturels de la vallée de l'Emscher participent activement au développement économique et social de ce territoire métropolitain en construction?

\section{Des retombées de la politique de flagship cultural project contrastées}

21 Dans les régions industrielles confrontées à la crise, urbanistes et élites politiques considèrent les grands projets d'équipements culturels comme un moyen d'assurer une reconversion économique et un renouveau urbain (Pfirsch et Reitel, 2014). Ainsi, une communication de Robin Boelsums à un colloque de la Regional Studies Association datant de 2012, identifie plusieurs objectifs que recherchent aménageurs et collectivités 
territoriales dans les flagship projects (qui comprennent notamment l'implantation de grands équipements culturels). Ces derniers espèrent :

- Redonner une image attractive au territoire ;

- Attirer des touristes, créer des emplois et favoriser l'investissement;

- Dynamiser la croissance et la santé économique du territoire ;

- Encourager l'investissement privé ;

- Redonner de la fierté aux habitants vis-à-vis de leur territoire.

L'implantation de grands équipements culturels dans la vallée de l'Emscher a-t-elle permis de répondre à ces enjeux? Telle est la thématique de la deuxième section de l'article qui s'appuiera sur l'exemple de quelques grands équipements culturels structurants de la Ruhr.

\section{Des projets entre architecture iconique et protection du patrimoine}

Dans des régions industrielles en crise, l'implantation d'équipements culturels d'envergure (flagship projects) vise à renverser l'image dépréciée de ces territoires dans l'optique de les rendre à nouveau attractifs pour les investisseurs étrangers (Doucet, 2009 ; Smyth, 1994). Ainsi, les projets d'équipements culturels cherchent à développer à tout prix une architecture iconique (Jencks, 2005) capable de marquer les esprits. C'est le cas de l'ancien lavoir de Hamm dans la Ruhr, complètement réhabilité en 1984 sous la direction de l'architecte-artiste Horst Rellecke. Ce dernier a adjoint à la structure du lavoir un éléphant de verre géant. Ce nouvel équipement culturel accueille désormais un centre d'exposition et un jardin tropical ornementé de sculptures cinétiques. Une telle démarche a inspiré les acteurs de l'IBA Emscher Park qui ont privilégié pour la réaffectation à des fins culturelles des sites industriels des architectes (Norman Foster pour le complexe minier de Zollverein) et des artistes contemporains de renom (Christo et Jeanne-Claude pour le gazomètre d'Oberhausen), illustrant ainsi parfaitement le néologisme de " starchitecture " développé par certains chercheurs (Gravari-Barbas, 2009). 


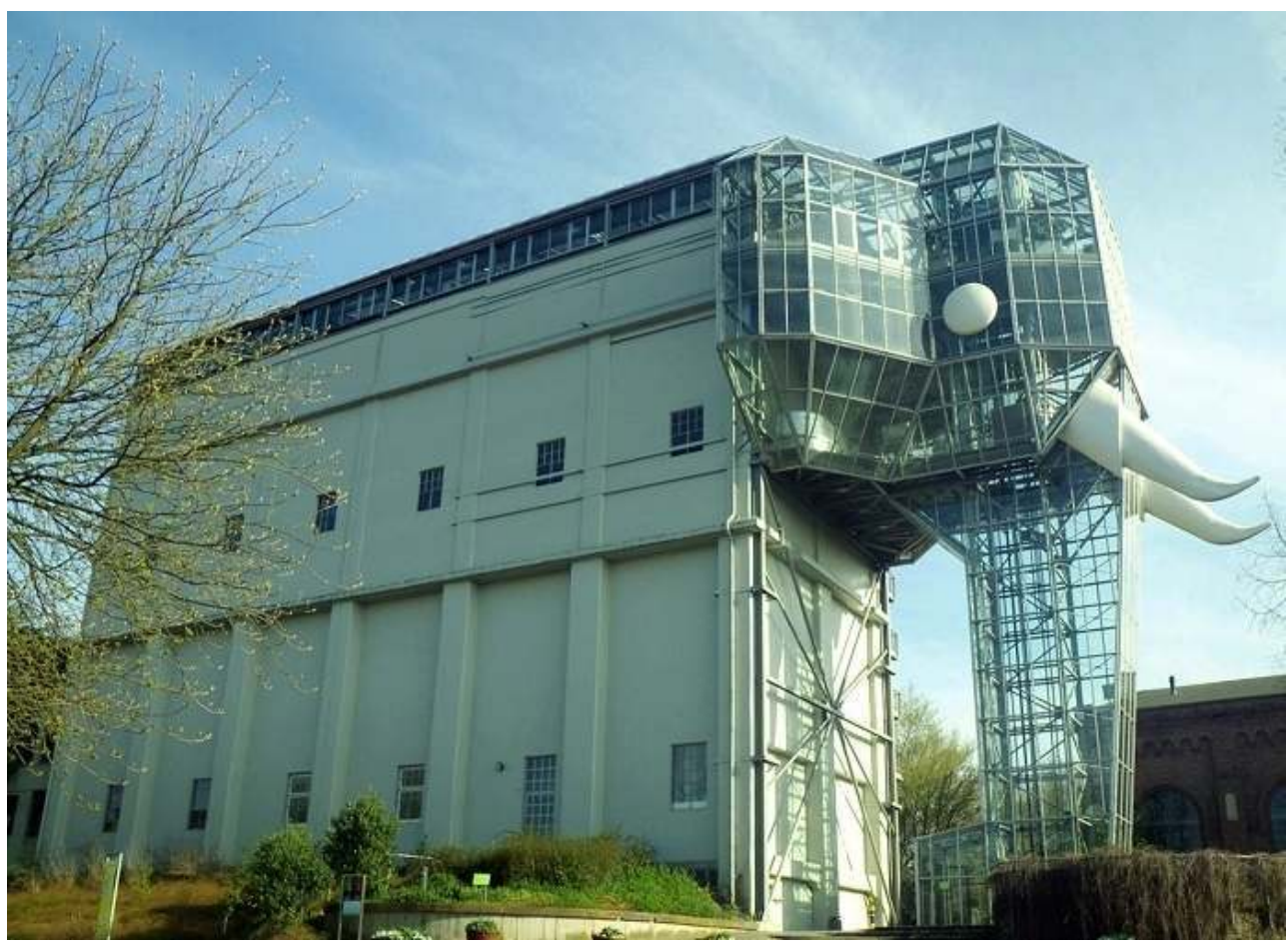

Photographie de Bruno Lusso, 2015, Lille 1, TVES

Dans la mesure où plusieurs infrastructures minières font l'objet d'une protection patrimoniale et dans l'optique plus ou moins avouée d'attirer un maximum de visiteurs (Doucet, 2009), l'enjeu pour ces architectes et paysagistes est donc de réussir à reconstituer l'ambiance industrielle du site originel. Pour la réalisation du Musée du Design à Essen installé dans l'ancienne chaufferie du complexe minier Zollverein qui disposait dès les années 1980 d'un dispositif de protection patrimoniale mis en place par le Land de Rhénanie du Nord-Westphalie (Prossek, Schneider, Wessel, Wetterau et Wiktorin, 2009), les travaux de réhabilitation chapeautés par Norman Foster sont minimes. Les objets sont directement exposés dans la cavité des chaudières dénoyautées, au beau milieu d'anciennes tuyauteries, permettant de mieux rappeler la fonction initiale du site. De la même manière, quand une construction moderne est adjointe à l'ensemble minier, celle-ci adopte souvent un style architectural proche : ainsi, l'Ecole du Design Zollverein réalisée par le cabinet SANAA est un hommage au style Bauhaus de la mine Zollverein. Cette approche visant à recycler l'ancienne friche minière tout en préservant l'authenticité du site industriel a facilité le classement du complexe Zollverein en décembre 2001 au Patrimoine Mondial de l'Humanité.

\section{Une insertion dans le cadre de projets de régénération urbaine plus larges}

Néanmoins, la réussite d'un projet de grand équipement culturel dépend de son inscription dans un environnement agréable (Bianchini, Dawson et Evans, 1992 ; Loftman et Nevin, 1995) diffusant une image du territoire positive et capable d'attirer des touristes aux revenus relativement élevés (Doucet, 2009). Or, ces projets d'équipements culturels 
privilégient majoritairement des quartiers périphériques confrontés à des problèmes d'accessibilité, de pollution et d'absence de qualités paysagères qui les placent en dehors du marché foncier (Bonneville, 2004). Comment "redonner de la lisibilité au lieu» (Barbier, 2002) afin que l'équipement culturel soit appréhendé comme un lieu culturel à part entière et non comme un élément nouveau mal intégré à un bâti urbain environnant fortement dégradé ? Il convient donc de travailler soigneusement sur l'aménagement des abords de l'équipement. Les terrils attenants aux anciens carreaux de mine revitalisés font l'objet d'un verdissement. De nouveaux signes urbains sont créés pour attirer le regard du visiteur. Ainsi, là où "manquent» des "monuments trouvés ", l'IBA invite artistes et sculpteurs à la création de repères nouveaux (Lefèvre, 2000). Une sculpture de 15 mètres de haut conçue par Richard Serra se dresse tel un totem sur le terril de Schurenbach qui surplombe le vaste complexe minier Zollverein reconverti en pôle culturel et créatif.

De ce fait, l'implantation d'un équipement culturel d'envergure stimule la régénération urbaine des quartiers environnants (Bianchini, Dawson et Evans, 1992 ; Grodach, 2010 ; Loftman et Nevin, 1995) et donc la croissance de secteurs urbains tombés en déshérence (Smyth, 1994 ; Grodach, 2010). C'est le cas du gazomètre d'Oberhausen situé sur un ancien site sidérurgique appartenant à la firme Thyssen et reconverti dès 1996 en centre d'exposition dédié aux nouvelles technologies. Ce projet s'inscrit dans le cadre d'une vaste opération de régénération urbaine appelée Neue Mitte. Investissant un périmètre de 143 hectares de friches industrielles attenantes au vieux Oberhausen, le projet vise à redynamiser le cœur de la ville par l'adjonction d'un nouveau centre au cadre de vie agréable et répondant aux besoins des habitants. Il s'agit aussi de diversifier les fonctions économiques d'un territoire longtemps resté industriel tout en offrant des fonctions urbaines « conformes » à celles d'une ville peuplée de plus de 200000 habitants.

Figure 5. L'opération urbaine Neue Mitte à Oberhausen.

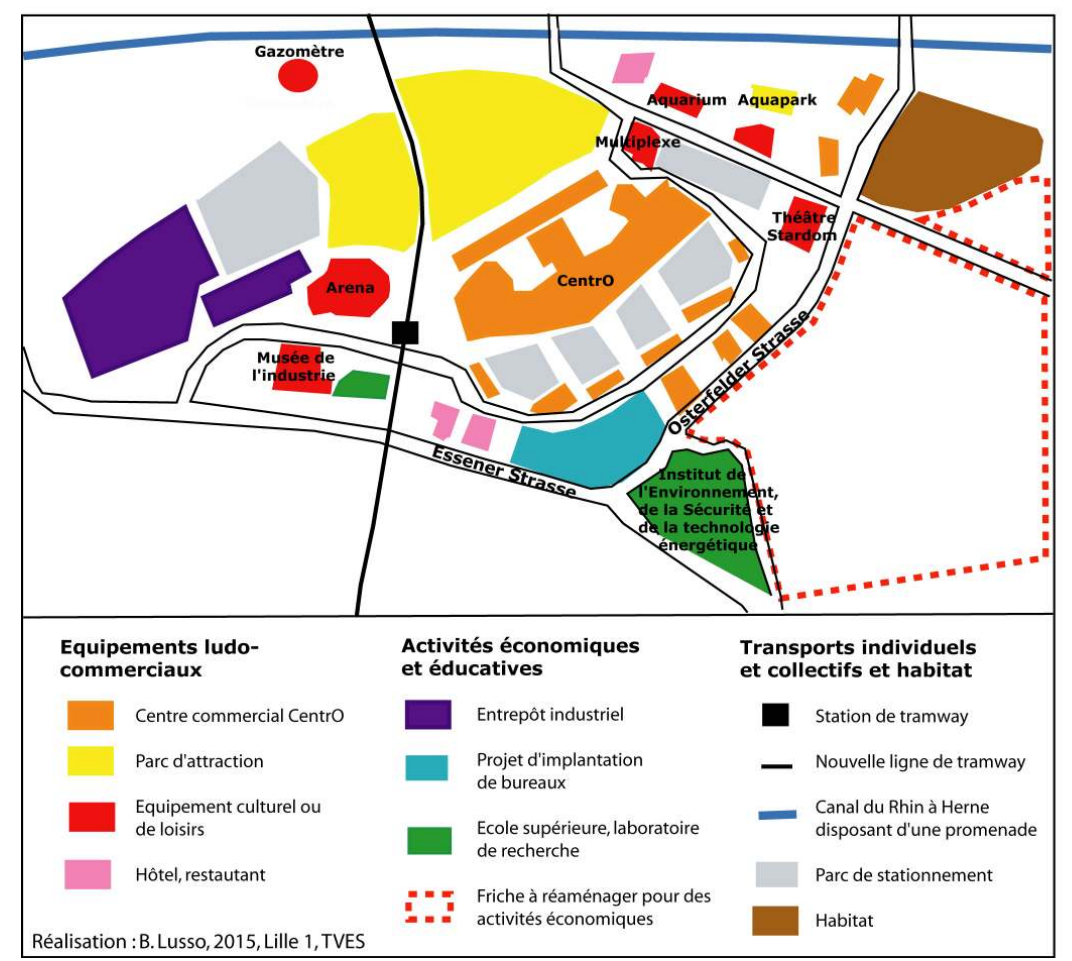


27 S’inspirant en partie du concept nord-américain des « Festival Market Places ", l'opération urbaine Neue Mitte qui résulte d'un partenariat entre la municipalité et des investisseurs britanniques dans le cadre de l'IBA Emscher Park, vise à créer une nouvelle centralité autour de l'économie des services, des loisirs et de la culture. Si le gazomètre d'Oberhausen qui accueille dès son ouverture en 1996 plus de 400000 visiteurs constitue la pierre angulaire du projet et un emblème symbolisant la transformation du territoire, il s'inscrit dans une offre culturelle beaucoup plus large (et potentiellement plus rentable qu'un équipement culturel isolé) comprenant notamment un aquarium, une aréna de 12650 places et un cinéma multiplexe.

28 Afin de retenir sur place les visiteurs, un complexe ludo-touristico-commercial baptisé Centr'O a été ouvert dès 1996 avec 220 magasins, une vingtaine de restaurants, plusieurs parcs d'attractions, un port de plaisance et une promenade de 400 mètres sur les rives du canal du Rhin à Herne. Le site a été désenclavé grâce à la construction d'infrastructures de transports nouvelles rendant le secteur accessible aux habitants d'Oberhausen (raccordement routier au centre-ville, construction d'une ligne de tramway avec un arrêt au cœur de la zone Neue Mitte), mais aussi aux visiteurs extérieurs (construction d'une sortie autoroutière au niveau du secteur). Afin de ne pas cantonner le nouveau centre à de simples activités ludo-récréatives, des immeubles de bureaux ont été construits pour accueillir des entreprises avec pour objectif de créer 2000 emplois d'ici 2020. L'habitat fait, lui aussi, l'objet d'une attention particulière. Il s'agit de répondre aux besoins croissants en matière résidentielle. Mais la construction de plusieurs unités d'habitat témoigne aussi de la volonté d'implanter des populations à proximité de leur lieu de travail, limitant ainsi la mobilité urbaine et empêchant le secteur de devenir une nouvelle centralité cantonnée à une vocation purement économico-récréative et dénuée de vie en dehors du temps consacré au travail et aux loisirs. C'est en ce sens qu'il faut comprendre les différents projets de construction de logements dans la zone Neue Mitte. Grâce à une fréquentation annuelle de 23 millions de personnes et à la création de 10000 emplois, l'opération Neue Mitte constitue une réussite contribuant à la revitalisation de la ville d'Oberhausen qui a perdu 43000 emplois. Si la création d'un équipement culturel contribue au même titre que les investissements en matière commerciale, de transport ou de développement économique à la revitalisation d'un territoire (Werquin, 2008), il ne faut pas oublier que ces ambitieuses opérations se font au détriment des centres urbains traditionnels des villes comme Oberhausen, Essen ou Dortmund qui n'ont pas connu le même degré de transformation (Kurth, Scheuvens et Zlonicky, 1999).

Majoritairement inscrite dans un programme de régénération urbaine plus large, l'implantation d'un équipement culturel a des effets directs sur la revalorisation foncière et immobilière des quartiers environnants (Loftman et Nevin, 1995). En effet, les logements des quartiers industriels majoritairement construits entre 1850 et 1960 pour répondre aux besoins de loger la main d'œuvre travaillant dans les usines, disposent généralement d'une valeur immobilière extrêmement faible, lorsque ceux-ci ne sont pas situés en dehors du marché foncier (Bonneville, 2004). Les entretiens ont révélé que l'implantation du Musée du Design Zollverein en 1997 a entraîné une augmentation des prix de l'immobilier dans le quartier de Katernberg supérieure de $20 \%$ à ceux de l'ensemble de la ville d'Essen alors que la réhabilitation des cités n'était pas engagée. Toutefois, certains chercheurs pointent le danger d'un processus de gentrification (Boelsums, 2012 ; Loftman et Nevin, 1995). C'est le cas notamment de la Rheinische Strasse localisée dans l'environnement direct du nouveau musée Ostwall à Dortmund où 
l'on constate depuis l'ouverture de l'institution en 2010 le déménagement des petites entreprises locales incapables de payer leur loyer au profit de banques et de compagnies d'assurances. De la même manière, les populations tendent à quitter le quartier en raison d'une pression immobilière devenue trop forte (Lauderbach, 2012), illustrant une logique de fragmentation socio-spatiale propre à l'implantation d'un grand équipement culturel dans des quartiers industriels (Eisinger, 2000; Temelova, 2007). En participant à la revalorisation foncière et immobilière, voire à un processus de gentrification du secteur dans lequel il s'implante, l'équipement culturel joue clairement un rôle dans la revalorisation de l'image territoriale.

\section{Le renversement de l'image en ligne de mire} vieilles régions industrielles. En effet, le concept d'image revêt deux dimensions complémentaires (Gueit, 2005) qui sont les suivantes :

- L'image interne, c'est-à-dire celle qui est vécue de l'intérieur, ressentie par les habitants et les organismes locaux. Elle renvoie à l'histoire, aux symboles et à la perception de l'évolution de la ville ;

- L'image externe, à savoir celle qui est ressentie de l'extérieur et qui permet de juger l'attractivité de la ville.

L'implantation d'un grand équipement culturel peut donc transformer les perceptions qu'ont les populations de leur territoire (Smyth, 1994). Les différents flagship cultural projects développés dans la Ruhr ont permis aux populations de prendre conscience d'un patrimoine longtemps ignoré, le patrimoine industriel (Soyez, 1999). La création des différents équipements culturels s'est faite avec la volonté de conserver le caractère industriel des sites, ce qui contribue à mettre en exergue l'identité collective du bassin de la Ruhr (Lusso, 2010). De plus, la transformation de la friche industrielle en équipement culturel est mise en scène par l'organisation de manifestations culturelles largement ouvertes aux populations permettant ainsi une meilleure appropriation. C'est le cas notamment du Landschaftspark de Duisbourg qui investit dans les années 1990 une ancienne aciérie Thyssen dont la salle des machines a été transformée en hall pour accueillir des événements culturels. Des installations lumineuses, des opéras, des technoparades, des séances de cinéma en plein air qui accueillent chacun plusieurs milliers de visiteurs locaux, sont organisés et permettent une meilleure prise de conscience du projet de parc paysager par la population. De tels projets permettent donc aux habitants de retrouver de la fierté pour leur région (Loftman et Nevin, 1995).

Dans un contexte de concurrence de plus en plus âpre entre les villes, chacune d'entre elles cherche à véhiculer une image positive, dans la perspective d'attirer investisseurs et nouvelles populations. C'est pourquoi, depuis les années 1980, les fonctions de marketing et de communication ont pris une place considérable dans le paysage et les politiques urbaines. Dans une visée électorale, les élus cherchent à vendre leur ville en lui donnant une image attractive. L'image et le projet de la ville sont donc intimement associés, mais « le projet précède toujours l'image » (Gueit, 2005), dans la mesure où il permet bien souvent à la ville d'apparaître sur les cartes (Rodriguez, Martinez et Guenaga, 2001). Ainsi, les équipements culturels implantés dans la vallée de l'Emscher sont devenus de véritables leviers des politiques de marketing urbain de la Ruhr. C'est en ce sens qu'il faut comprendre la candidature des 53 communes de la Ruhr au titre de Capitale européenne

Belgeo, 3 | 2014 
de la culture pour l'année 2010. Le slogan de la candidature lancée sous la direction de la ville d'Essen, « le changement grâce à la culture et la culture grâce au changement " (" Wandel durch Kultur - Kultur durch Wandel »), cherche à souligner la réussite de la transformation structurelle de la région grâce à la culture et aux équipements culturels. La candidature de la Ruhr se concentrait sur les sujets de l'urbanité, de l'identité et de l'intégration. L'attribution en 2006 du titre de Capitale européenne de la culture récompense le paysage culturel de la Ruhr avec notamment le complexe culturel Zollverein, le théâtre Aalto, le musée Folkwang ou le gazomètre d'Oberhausen reconverti en centre d'exposition. S'il est indéniable que les équipements culturels ont clairement contribué au renversement de l'image interne et externe de la Ruhr, qu'en est-il concrètement de leurs retombées économiques et sociales?

\section{Des retombées économiques et sociales globalement limitées}

Les effets de la culture et de la création sur la croissance économique et le développement des territoires sont tangibles, principalement au travers de l'essor du tourisme (Origet du Cluzeau et Tobelem, 2009). L'envergure d'un projet de grand équipement culturel fait qu'il attire dès son ouverture un grand nombre de visiteurs (inter)nationaux (Doucet, 2009) stimulant ainsi l'économie touristique locale (Bianchini, Dawson et Evans, 1992). La Ruhr, et plus spécifiquement la vallée de l'Emscher, illustrent parfaitement ce processus. En effet, le secteur touristique dans la Ruhr, jusque-là quasiment inexistant, a véritablement explosé au cours des années 2000 , si bien que 2,4 millions de touristes ont effectué en 2008 un séjour dans la vieille région industrielle. Si les parcs à thème (piste de ski de l'Alpincenter sur un ancien terril à Bottrop) ou les centres ludo-commerciaux (CentrO à Oberhausen) arrivent en tête des sites les plus visités, les équipements culturels créés sur d'anciennes friches industrielles ne sont pas en reste. Les musées du Design d'Essen et de la mine Zollern ont dépassé en 2010 le cap des 200000 visiteurs annuels, le gazomètre d'Oberhausen ou le Ruhrlandmusuem atteignent même les 450000 visiteurs, témoignant de la vitalité du tourisme industriel régional. Si les visiteurs sont aux deux tiers des excursionnistes habitant la Ruhr, on constate néanmoins un accroissement des touristes issus des autres Länder allemands et des touristes étrangers (Belges et Néerlandais principalement) qui représentent respectivement 15 et $20 \%$ de la clientèle de ces équipements culturels.

Toutefois, les entretiens effectués auprès des équipements culturels ont révélé que le nombre de visiteurs varie fortement selon les années. Les phases de croissance et de décroissance se succèdent, montrant ainsi la dépendance d'un équipement culturel à la conjoncture. Ainsi, le Musée du Design localisé dans l'enceinte du complexe minier Zollverein qui accueille en moyenne 100000 à 150000 visiteurs a connu durant certaines années un recul sensible du nombre total de ses entrées, notamment en 2002-2003 (-10\% de visiteurs) et en 2007-2010 (-20\% de visiteurs en raison de la crise économique). Une telle variabilité peut entraîner les équipements culturels dans une situation extrêmement délicate. C'est le cas du Ruhrlandmuseum qui, en dépit de son transfert sur le site Zollverein en 2008, n'a pas réussi à résorber un déficit financier qui ne cesse de s'accroître au fil des années (Lusso, 2013). Aujourd'hui, environ $50 \%$ des équipements culturels de la vallée de l'Emscher sont en situation de déficit, démontrant ainsi les limites du modèle d'autogestion des structures culturelles voulu par le Land dans le cadre de l'IBA. Certaines personnes rencontrées dans le cadre de cette étude estiment même qu'il faudrait injecter 
chaque année 100 millions d'euros pour assurer le bon fonctionnement de ces structures culturelles qui se révèlent être davantage des gouffres financiers que des moteurs du développement économique des territoires. Loin d'améliorer la situation financière des territoires en question (Grodach, 2010), la politique du flagship cultural projects représente souvent un risque financier pour les collectivités dans lesquelles l'équipement s'implante (Loftman et Nevin, 1995 ; Eisinger, 2000 ; Temelova, 2007).

35 A défaut de trouver un excédent financier, quelles solutions peuvent s'offrir aux équipements culturels pour assurer l'équilibre budgétaire? Le développement des activités commerciales (boutique, restaurant, librairie, accueil de colloques) pourrait être une solution (Bayart et Benghozi, 1993). Mais celle-ci a ses propres limites, dans la mesure où elle génère, notamment en période de crise, des recettes très limitées. Une autre possibilité offerte aux équipements culturels de trouver des ressources complémentaires réside dans le développement d'une programmation culturelle (expositions temporaires) et événementielle (défilés, parades, organisation de colloques). Les mécènes et les sponsors sont également sollicités (Lusso, 2008). Alors que le Land de Rhénanie du NordWestphalie et la ville de Dortmund participent activement au financement d'un centre d'éducation culturelle implanté dans l'ancienne brasserie Dortmunder U, le musée Ostwall situé dans le même bâtiment doit assurer quant à lui ses dépenses de fonctionnement sur des fonds propres. Il en découle une recherche accrue de financements extérieurs qui passe notamment par la création d'une société des Amis du Musée. Le mécénat d'entreprise est également encouragé, mais rencontre des fortunes diverses. Si les partenariats culturels et associatifs sont multiples (Fondation du Land de Rhénanie du Nord-Westphalie pour l'art, Institut Goethe...), une seule entreprise (Vorweg Gehen) s'est engagée dans une logique de mécénat avec le musée Ostwall.

De nombreux sociologues considèrent que les équipements culturels ont avant tout une mission sociale (Ballé et Poulot, 2004 ; Bayart et Benghozi, 1993) et doivent permettre un accès à la culture au plus grand nombre (Passeron, 2005). Mais un rapide aperçu de la fréquentation de trois équipements culturels emblématiques de la vallée de l'Emscher (Musée du Design à Essen, musée Ostwall à Dortmund et gazomètre d'Oberhausen) met sérieusement en doute l'objectif de démocratisation culturelle. En effet, les publics côtoyant chacune de ces trois institutions sont essentiellement des scolaires $(50 \%$ des visiteurs) et, dans une moindre mesure, des personnes appartenant à des catégories socio-professionnelles relativement élevées (les cadres représentent entre 20 et $25 \%$ des visiteurs des trois institutions). Les populations socialement défavorisées demeurent un public très marginal (entre 10 et $15 \%$ du nombre total de visiteurs), et ce en dépit de grilles tarifaires qui peuvent leur être très favorables. Le musée Ostwall propose une entrée à un tarif réduit de 2,50 euros (le tarif plein est de 5 euros) pour les enfants, les élèves et étudiants, les détenteurs d'un pass et les chômeurs. Il faut reconnaître que ces populations confrontées à des profondes difficultés sociales, se sentent peu concernées par les questions culturelles et préfèrent consacrer une plus large partie de leur budget mensuel à la satisfaction de leurs besoins fondamentaux.

Une telle situation pousse les responsables des différents équipements culturels à mettre en place des politiques visant à attirer les personnes issues des quartiers environnants. A Dortmund, un Centre d'éducation culturelle est même créé dans l'enceinte du musée. Par le biais d'ateliers, le centre vise à stimuler la créativité du jeune public par l'utilisation des nouvelles technologies de l'information et de la communication. Les participants peuvent ainsi créer une séquence vidéo ou une composition musicale qui sera ensuite 
exposée sur la plate-forme de présentation des œuvres d'art du musée Ostwall, le Hartware MedienKunstVerein. L'enjeu de ces politiques de médiation est de créer un lien actif entre l'enfant et l'œuvre. Le jeune public devient acteur et non plus un simple visiteur. Ces ateliers qui sont prolongés auprès d'un public adulte dans une optique de réinsertion sociale par la culture, ont néanmoins des résultats globalement mitigés. $\mathrm{Si}$ enfants et adultes peuvent développer des pratiques culturelles et artistiques, leurs effectifs très limités n'entraînent pas un retour massif de ces populations vers la culture d'autant que ces actions nécessitent un investissement humain très important. Pourtant, ces équipements culturels ne sont pas franchement de gros pourvoyeurs d'emplois, allant de trois personnes pour les plus petites institutions (musée Ickern) à une centaine de personnes pour les infrastructures les plus importantes (musée du Design d'Essen, mine Zollern). Parmi ces salariés, un tiers d'entre eux est affecté à des tâches d'accueil, d'entretien, de vente de produits dérivés, de restauration et de surveillance. Principalement détenteurs de contrats à durée déterminée, ces travailleurs occupent des emplois faiblement qualifiés. A l'inverse, moins de $20 \%$ de salariés assurent des fonctions purement muséographiques telles que la médiation, la préparation d'expositions temporaires, l'édition de brochures et d'ouvrages, les activités de recherche scientifique et de direction. Il en résulte de fortes différences salariales qui peuvent aller de 1 à 10 , notamment pour le musée Ostwall de Dortmund. Loin de gommer les ségrégations sociales, l'institution muséale tend au contraire à prolonger en son sein ces inégalités.

En dehors d'une revalorisation de l'image territoriale, les équipements culturels de la vallée de l'Emscher génèrent, en dehors de l'économie touristique et culturelle, un impact économique direct extrêmement faible pour un coût financier indéniable. Ils déçoivent également sur le plan de la démocratisation culturelle et n'apportent pas les emplois tant espérés par les aménageurs et les édiles. Si l'équipement culturel peut être considéré comme un lieu d'exception, il ne peut pas constituer un pôle d'excellence (Lévy, 1995) et procurer un avantage métropolitain (Halbert, 2010). Il faut pour cela disposer de ressources diversifiées (Bailoni, 2014). La réussite d'un équipement culturel dépend en grande partie de son insertion dans le cadre de projets de régénération urbaine plus larges associant des politiques en matière de transports, d'habitat, d'environnement et de développement économique (Werquin, 2008). Enfin, la pérennisation de ces équipements culturels nécessite de lourds investissements, notamment en matière d'événementiel, qu'il convient de présenter.

\section{Miser sur les industries culturelles et créatives pour pérenniser la dynamique territoriale : une bonne idée?}

Le bilan de la régénération urbaine par les seuls équipements culturels est globalement mitigé (Lusso, 2011). En 2011, la Commission européenne a révélé que l'économie culturelle et créative représentait 3,3\% du PIB européen et 6,7 millions de salariés, soit $3 \%$ de l'emploi européen. Entre 2008 et 2011, l'emploi dans les domaines de la culture et de la création a été l'un des plus résistants à la crise économique (Commission européenne, 2012). Conscients des retombées des industries culturelles et créatives en termes d'image et de développement économique, de nombreux territoires cherchent à se spécialiser sur un créneau culturel ou une industrie créative (Gravari-Barbas et Violier, 2003). Quelles solutions la Ruhr - et plus précisément la vallée de l'Emscher - a retenu 
pour assurer la pérennisation des équipements culturels, mais aussi pour approfondir la construction de l'ensemble métropolitain?

\section{Pérenniser la dynamique culturelle par l'événementiel}

Les équipements culturels existent principalement au niveau national et international de par les grands événements qu'ils accueillent (Fagnoni, 2009). Pour l'équipement culturel, il s'agit de maintenir, voire de renouveler (augmenter) le nombre de visiteurs, élément indispensable à sa pérennisation (Lusso, 2013). Les sites patrimoniaux sont donc investis par des médiations festives de plus en plus sophistiquées (mises en lumière, projections, théâtralisation) (Gravari-Barbas, 2009). C'est en ce sens qu'il faut comprendre l'organisation depuis 1997 d'une exposition horticole annuelle sur le site minier Nordsternpark à Gelsenkirchen (Ruhr). De la même manière, de grandes expositions internationales sont organisées dans le gazomètre d'Oberhausen ou dans la salle des compresseurs de la cokerie Hansa à Dortmund. Certaines friches minières ont même été spécialement réhabilitées pour accueillir les activités événementielles organisées dans le cadre du Klavier-Festival Ruhr, un festival de musique classique lancé en 1989, ou de l'emblématique Ruhrtriennale, un festival culturel organisé tous les trois ans depuis 2002 et financé par le Land de Rhénanie du Nord-Westphalie. Ces manifestations culturelles investissent de manière préférentielle des lieux chargés d'histoire et vecteurs d'une appropriation par les populations locales comme une centrale électrique reconvertie en salle de spectacles, Jahrhunderthalle de Bochum, ou un amphithéâtre plein air de 800 places localisé au sommet du terril Haniel à Bochum.

De ce fait, la politique de flagship cultural projects nécessite et s'appuie de plus en plus sur une programmation événementielle récurrente (festivals, plages, nuits blanches) ou exceptionnelle (capitale européenne de la culture, exposition internationale) (Fagnoni, 2009). Selon D. Getz (2007), de par leur envergure nationale ou internationale, les grands événements produisent des retombées très positives sur l'image territoriale, la cohésion sociale et l'économie locale. D'une durée limitée dans le temps et l'espace, ces manifestations qui peuvent être d'ordre culturel, artistique, festif, commercial ou sportif, ont pour principal objectif d'attirer l'attention des médias et visiteurs (Burbank, Andranovich et Heying, 2005). Cette nécessité d'une large couverture médiatique de l'événement pousse les décideurs politiques à créer des nouveaux équipements qui s'inscrivent souvent dans le cadre d'ambitieux programmes de régénération d'espaces urbains tombés en déshérence (Smith, 2012). Quant aux artistes, l'organisation d'un événement culturel est un facteur pouvant stimuler leur créativité et leur production (Markusen, 2006), notamment grâce à un nombre plus élevé de commandes publiques et/ ou privées. Le choix retenu par les organisateurs de mettre en scène ces manifestations entraine dans la plupart des cas une mobilisation massive des populations (Roche, 2006).

La vallée de l'Emscher a connu une dynamique de ce type avec l'organisation en 2010 de la Capitale européenne de la culture. Pour assurer l'organisation de l'événement, une société de droit privé, RUHR. $2010 \mathrm{GmbH}$, a été créée et travaille en étroite collaboration avec la ville d'Essen, l'Association régionale de la Ruhr, le Land de Rhénanie du NordWestphalie et le Cercle d'Initiatives de la Région de la Ruhr (Initiativkreis Ruhrgebiet). Trois grandes thématiques " Urbanisme », «Identité » et "Intégration » ont été retenues et se sont articulées autour de quatre champs d'action " Ville des possibilités ", "Ville des arts », « Ville des cultures » et « Ville de la créativité ». L'année culturelle a été ponctuée 
de 5500 manifestations culturelles qui se sont appuyées sur un riche réseau de friches industrielles. Ainsi, 400 ballons jaunes ont été disposés à 80 mètres au-dessus des anciens puits de mine, rappelant à la fois l'exploitation minière et les changements structurels régionaux. Quant au festival Extraschicht organisé chaque année depuis 2001, il propose dans le cadre des installations industrielles de la Ruhr des mises en lumière, spectacles, concerts ou performances artistiques, et est devenu, grâce à sa fréquentation record en 2010 (200 000 visiteurs en une nuit), un temps fort de l'année culturelle. A Gelsenkirchen, le site minier Nordsternpark a accueilli la fête de clôture de l'année culturelle. Certains équipements ont été créés sur d'anciennes friches industrielles (centre d'art contemporain dans une ancienne brasserie de Dortmund), d'autres ont déménagé (musée de la Ruhr sur le complexe minier Zollverein) ou se sont agrandis (extension du musée d'art moderne et contemporain ouvert à Duisbourg en 1999 dans un ancien entrepôt du port intérieur). Plusieurs créations ont survécu, à l'instar du spectacle de danse urbaine Urbanatix, initialement présenté dans la Jahrhunderthalle de Bochum.

Il est donc évident que l'organisation d'un tel événement - en dépit de son coût très élevé souvent estimé à plusieurs dizaines de millions d'euros - stimule fortement l'économie touristique locale (Robertson et Frew, 2008), même si la dynamique peut s'avérer très éphémère (Essex et Chalkley, 2004). Ainsi, dans la vallée de l'Emscher, l'année culturelle a attiré 10,5 millions de visiteurs et entraîné une hausse de $13 \%$ des nuitées. L'activité touristique s'est même maintenue après l'événement Ruhr 2010 avec une hausse en 2011 de $10 \%$ des recettes touristiques, là où d'autres villes ont vu l'engouement retomber très fortement à la suite de l'année culturelle. Il est indéniable que les villes de la vallée de l'Emscher ont parachevé le renversement de leur image externe. Désormais, la Ruhr n'apparaît plus comme une région industrielle perpétuellement en crise, mais comme un véritable ensemble métropolitain multipolaire qui a réussi à construire un projet collectif articulé autour de la culture (Zepf et Andres, 2011). Mais une telle réussite apparente a ses revers. L'année culturelle s'est révélée être un véritable gouffre financier pour les villes de la Ruhr. En raison de la défection des sponsors et mécènes, le budget de l'année culturelle a été amputé de 20 millions d'euros pour atteindre cependant la coquette somme de 62,5 millions d'euros. Supporté en grande partie par les collectivités territoriales, il a contribué à creuser un peu plus le déficit financier structurel de certaines communes de la Ruhr. Malgré tout, l'enjeu principal de nombreuses villes organisatrices d'événements culturels est de pouvoir inscrire l'éphémère sur le long terme, dans une optique de développement urbain (Gras, 2007). Si un organisme de promotion de la culture est d'ores et déjà envisagé, une question cruciale se pose néanmoins : comment poursuivre et approfondir une telle dynamique dans une région métropolitaine en défaut de paiement?

\section{Miser sur le développement de quartiers culturels et créatifs}

Bien avant même l'organisation de l'année culturelle, le Land de Rhénanie du NordWestphalie a envisagé d'étendre aux activités créatives la réhabilitation des friches industrielles. De nombreux chercheurs pensent que la crise qui caractérise les villes et, à une échelle plus fine les friches industrielles, constitue aussi une période charnière annonçant un éventuel renouveau (Hall, 1998). En raison de leur situation périphérique dans des quartiers tombés en déshérence, ces friches ont pu accueillir des artistes en marge et/ou désargentés qui ont réinvesti ces lieux soit de manière légale ou sous la forme de squats. Ainsi, se crée un terreau favorable à l'émulation créative et à 
l'innovation artistique (Lucchini, 2012). Pourtant, un processus de réhabilitation des friches par les activités culturelles ou créatives est amorcé dès la fin des années 1960 (Grésillon, 2008). Longtemps restées des lieux spontanés et sauvages occupés par des collectifs d'artistes en opposition idéologique avec le pouvoir dominant, ces friches culturelles changent de nature à la fin des années 1980. Leurs occupants n'étant plus en opposition systématique avec le pouvoir, elles reçoivent désormais le soutien des pouvoirs publics qui ont clairement compris l'enjeu que pouvaient représenter les artistes dans ces friches en matière d'image culturelle. En effet, certaines collectivités territoriales vont jusqu'à reconstituer des lieux de création artistique dans d'anciennes friches industrielles désaffectées. C'est le cas dans la Ruhr de l'ancienne mine Ewald à Herten fermée en 2001 et transformée en une friche théâtrale occupée par la compagnie RevuePalast qui réalise des spectacles transformistes. Afin d'assurer une bonne diffusion locale des différentes créations de la compagnie, la chaufferie de la mine Ewald a été transformée en un véritable cabaret, faisant du site un lieu de création et de diffusion culturelle.

A la fin des années 1990, une nouvelle étape est franchie. En matière d'action publique, la planification de clusters culturels au sein de quartiers labellisés "culturels et créatifs ", ou d'« industries culturelles », est devenue une " orthodoxie de l'aménagement et de la revitalisation urbaine » (Scott, 2004). Dans la vallée de l'Emscher, les pouvoirs publics ont encouragé le développement des industries créatives ou culturelles sur les anciennes friches industrielles. C'est le cas de l'immense complexe minier Zollverein d'Essen, sur lequel est envisagée à la fin des années 1990 la création de toutes pièces d'une «ville du design ». Ainsi, une surface de $35000 \mathrm{~m}^{2}$ a été réservée dans l'environnement direct du Musée du design ouvert en 1997 pour favoriser l'implantation d'entreprises, de logements et d'ateliers destinés aux jeunes créateurs dans le domaine des médias et du design. Le développement du site s'est poursuivi avec la création de la Zollverein School of Management and Design qui est aussi un laboratoire pour les arts, l'architecture et le design. L'école, ouverte en 2006, devait accueillir environ 600 étudiants et favoriser les passerelles entre le monde de la formation, de la recherche et les entreprises. Mais les prix d'inscription et de scolarité très élevés (1 600 euros par an en moyenne) ont entraîné la fermeture rapide de l'école. Le site a été repris en 2010 par le département design de l'Université de Folkwang. Une extension du site est prévue, mais bute sur son financement que le Land de Rhénanie du Nord-Westphalie souhaite faire supporter par des investisseurs privés. 


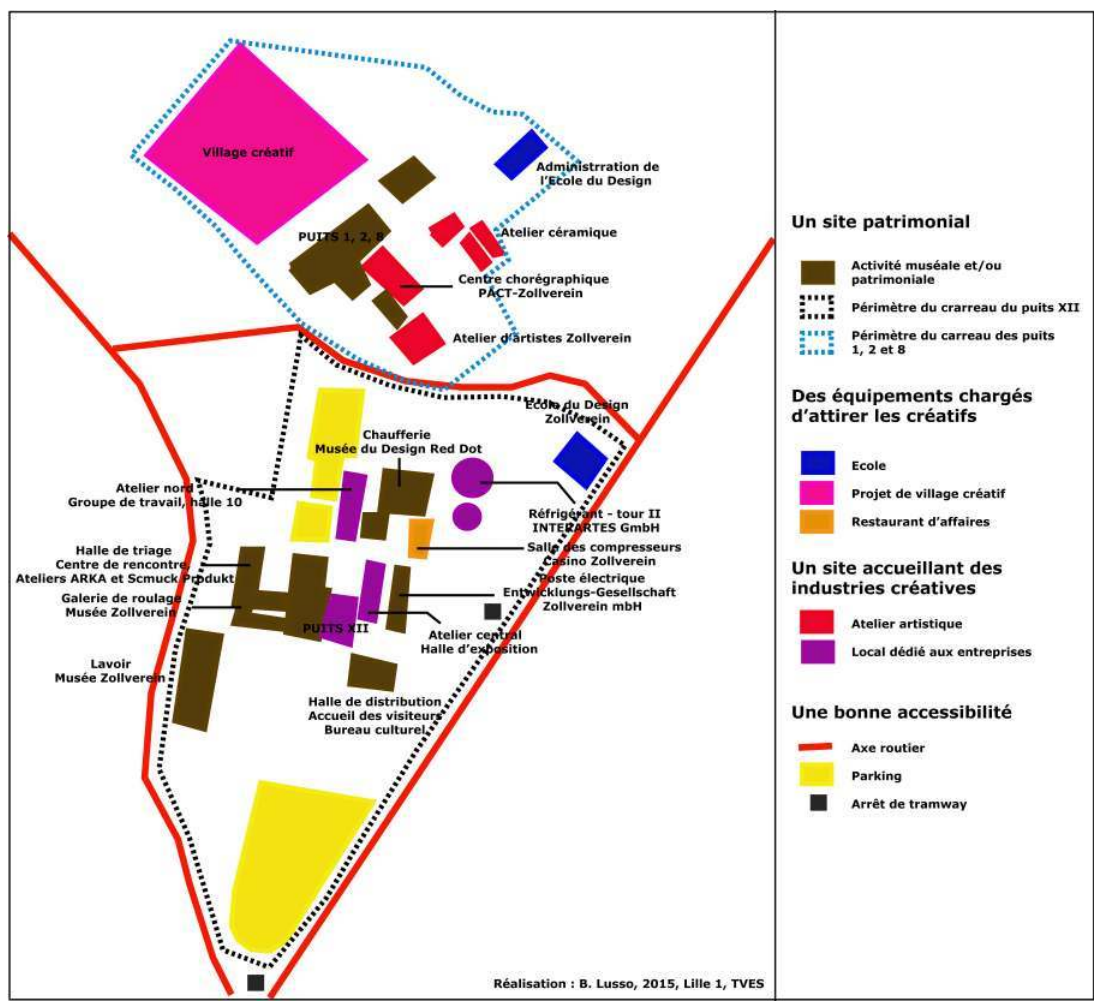

D'un point de vue entrepreneurial, les pouvoirs publics espéraient l'implantation de 1300 bureaux de design à l'horizon 2010. Or, nous sommes très loin de ces projections dans la mesure où seulement une vingtaine d'entreprises se sont implantées sur le site, ce qui représente moins de $2 \%$ des créations envisagées... C'est le cas de la société GrafBeyle spécialisée dans le film et le design d'animation qui réalise les décors pour quelques émissions de la chaîne culturelle franco-allemande Arte ou de la SARL Lichtdesign und Klangkonzept orientée vers le design lumineux et la conception sonore. Plus inquiétant encore, après une dizaine d'années d'activité, le quartier créatif Zollverein peine à être rentable. Si les activités liées au design ont généré un peu plus de 400 millions d'euros depuis 2005, leur maintien a coûté la bagatelle de 155 millions d'euros à l'Union européenne, au Land de Rhénanie du Nord-Westphalie et à la ville d'Essen. Dans de telles conditions, il parait tout à fait logique que le projet de village créatif devant accueillir un hôtel, des bureaux et une résidence étudiante, soit resté depuis 2005 dans les cartons. Les négociations difficiles avec l'investisseur principal - le coût du village créatif est estimé à 140 millions d'euros - et les résultats économiques mitigés de la "ville du design" auraient eu raison du projet. Ainsi, loin d'être devenue la "cité du design" imaginée par les aménageurs et les édiles, le site Zollverein conserve principalement une vocation touristique et patrimoniale (Lusso, 2010).

\section{Faire de la Ruhr une métropole créative}

Malgré les résultats décevants de la "cité du design ", le Land de Rhénanie du NordWestphalie a mis en place au tournant des années 2010 une stratégie visant à faire de la Ruhr une métropole créative. Cet intérêt récent pour les questions relatives à la créativité provient principalement du succès des thèses sur la ville créative. En effet, à partir du 
milieu des années 1990, les travaux de l'urbaniste-sociologue Charles Landry ont cherché à mettre en évidence les relations entre créativité et développement des territoires. Son ouvrage, The Creative City: A toolkit for urban innovators, sorti en 2000, a permis de populariser la notion de ville créative au sein de la communauté scientifique. Son questionnement sur la ville créative provient de l'analyse de la crise urbaine qui a affecté un bon nombre de villes industrielles anglaises au cours des années 1970 et 1980 . Ces villes, après avoir tenté en vain diverses alternatives économiques de sortie de crise, ont cherché, avec succès parfois, à trouver des ressources de redéploiement en régénérant par la culture et les industries créatives d'anciens quartiers industriels tombés en déshérence. A partir de ce constat, Charles Landry développe l'idée que la créativité ne se situe pas seulement du côté du marché du travail, mais qu'elle est aussi au cœur de l'urbanisme. Pour lui, les décideurs publics doivent être en mesure de créer le cadre urbain qui permette aux créatifs de s'épanouir. De ce fait, les politiques publiques doivent être capables de développer un projet culturel d'envergure gourmand en capitaux publics, mais aussi de répondre à des impératifs en matière de développement économique. La culture du territoire peut donc devenir un atout dans le sens où elle permet l'activation d'une identité propre au territoire tout en la faisant s'ouvrir et dialoguer avec le monde. La notion développée par Charles Landry inscrit clairement la problématique de la ville créative dans un questionnement européen autour de la gestion de la crise urbaine et de la revitalisation des villes avec une forte implication des pouvoirs publics. En ce sens, elle se distingue très clairement de la théorie de Richard Florida développée au même moment à partir de l'exemple des villes nord-américaines où l'intervention publique dans les processus de régénération urbaine et culturelle est beaucoup plus limitée.

Dans son ouvrage The Rise of the Creative Class publié en 2002, l'économiste américain Richard Florida avance l'idée d'une corrélation certaine entre la présence d'une classe créative dans les grandes villes et d'un haut niveau de développement économique. Travaillant sur la structure de l'emploi des villes, Richard Florida identifie la classe créative comme une population urbaine, mobile, qualifiée et connectée. Cette classe créative se localise en fonction de trois paramètres: la technologie, le talent et la tolérance. Si la technologie intimement liée aux dynamiques d'innovation ne fait pas débat, les deux autres catégories paraissent toutefois beaucoup moins communes. Les personnes dotées d'un talent défini chez Richard Florida simplement en fonction du niveau d'études, sont attirées par les villes qui disposeraient d'une vie culturelle dynamique avec des équipements culturels de qualité, des festivals ou une importante vie nocturne. La présence dans ces villes de minorités visibles (communautés étrangères ou homosexuelles, quartiers branchés d'artistes qualifiés de «bohémiens » et animant une culture off) encouragerait un dépassement des idées conventionnelles et une ouverture des talents dont la créativité serait stimulée. Ainsi se crée un cercle vertueux, le talent attirant le talent, mais aussi les entreprises, le capital et les services. Pour appuyer ses thèses, Richard Florida a mis en place une batterie d'indicateurs statistiques comme le Gay Index ou le Bohemian Index, censés mesurer l'attractivité d'une ville à partir du nombre d'artistes et d'homosexuels qui y sont implantés. Néanmoins, ses indicateurs, tout comme sa définition de la ville créative, suscitent une vive polémique au sein de la communauté scientifique. En effet, de nombreux programmes de recherche internationaux tentent de vérifier la validité de la thèse de Richard Florida (Programme ACRE, Chantelot, 2006). Les 
critiques se multiplient, notamment sur les choix méthodologiques qu'il a retenus (Levine, 2004 ; Tremblay, 2006 ; Vivant, 2006 ; Tremblay et Tremblay, 2010).

En dépit des nombreuses critiques sur le plan conceptuel, le Land de Rhénanie du NordWestphalie n'a pas renoncé à sa volonté de développer les industries créatives à l'échelle de la Ruhr désormais considérée comme une région métropolitaine (Zepf et Andres, 2011). Un groupe de réflexion sur la "ville de la créativité » est mis en place durant les travaux préparatoires à l'organisation de l'année culturelle. Celui-ci a souligné l'absence de stratégie régionale suffisamment claire dans le développement de l'économie créative. C'est pourquoi à l'initiative du Land de Rhénanie du Nord-Westphalie et de l'Association régionale de la Ruhr est créé en 2011 un Centre européen pour l'économie créative (Ecce) qui travaille en étroite collaboration avec les artistes, les créateurs, les municipalités, ainsi que les organismes de planification urbaine, économique et culturelle. Pour favoriser la concrétisation des différents projets créatifs, une agence de développement économique, la Wirtschaftsförderung Metropoleruhr $\mathrm{GmbH}$, voit le jour. Celle-ci lance avec le concours du Land et d'Ecce le programme Kreativ.Quartiere Ruhr qui identifie à l'échelle régionale 11 quartiers créatifs potentiels localisés autour d'anciennes friches industrielles. Les moyens humains et financiers seraient concentrés sur ces sites qui contribueraient au changement de trajectoire économique de la métropole Ruhr. 
Tableau 1. Les « Kreativ.Quartiere » de la Ruhr.

\begin{tabular}{|c|c|c|}
\hline Nom du quartier & Localisation (ville) & Thématique principale \\
\hline $\begin{array}{ll}\text { KQ } & \text { Viktoria } \\
\text { Quartier } & \end{array}$ & Bochum & $\begin{array}{l}\text { Cultures urbaines et sous-culture (musique } \\
\text { électronique, slam, théâtre...) }\end{array}$ \\
\hline KQ Lohberg & Dinslaken & $\begin{array}{l}\text { Arts visuels (galeries, ateliers de peintres et de } \\
\text { photographes) et musique }\end{array}$ \\
\hline KQ Unionviertel & Dortmund & Art contemporain \\
\hline KQ Ruhrort & Duisbourg & Industrie du multimédia \\
\hline $\begin{array}{ll}\text { KQ } & \text { City Nord } \\
\text { Essen }\end{array}$ & Essen & Design, mode, galeries d'art, boutiques \\
\hline KQ Ückendorf & Gelsenkirchen & Equipements culturels divers \\
\hline KQ Wanne & Herne & $\begin{array}{l}\text { Cultures urbaines (danse, arts visuels...), cafés, } \\
\text { magasins et équipements culturels }\end{array}$ \\
\hline KQ Herten Süd & Herten & Equipements culturels et troupe théâtrale \\
\hline $\begin{array}{ll}\text { Game } & \text { Factory } \\
\text { Ruhr } & \end{array}$ & $\begin{array}{l}\text { Mülheim an der } \\
\text { Ruhr }\end{array}$ & Jeu vidéo \\
\hline $\begin{array}{ll}\text { KQ } & \text { Oberhausen } \\
\text { Mitte } & \end{array}$ & Oberhausen & Equipements culturels et studios de création \\
\hline KQ Wiesenviertel & Witten & Arts visuels et cafés \\
\hline
\end{tabular}

Réalisation : B. Lusso, 2015, TVES, Lille 1, d'après http://www.kreativ-quartiere.de/

Parmi les différents secteurs urbains de la Ruhr labellisés Kreativ.Quartiere, nous pouvons distinguer selon le contexte territorial cinq grandes catégories :

- Des secteurs urbains déjà planifiés comme des quartiers créatifs et bénéficiant depuis plusieurs années de financements privés et publics importants (KQ Herten Süd autour de la troupe RevuePalast ou KQ City Nord Essen dans lequel s'inscrit la cité du design Zollverein).

- D'anciennes friches industrielles ou commerciales réinvesties par des artistes locaux dans le cadre de squats légalisés par la puissance publique (KQ Wanne à Herne développé à partir d'un collectif de danseurs et de musiciens ayant occupé un magasin désaffecté).

- D'anciens bâtiments industriels réhabilités dans lesquels est réalisée une greffe culturelle (Game Factory Ruhr à Mülheim an der Ruhr).

- D'anciens quartiers industriels et localisés en périphérie des villes, historiquement marqués par les activités culturelles et créatives (le KQ Ruhrort situé à proximité du port de Duisbourg et désormais dédié à l'industrie du multimédia, a servi depuis les années 1970 de lieu de tournage de la série allemande Tatort).

- Des quartiers centraux ou péricentraux définis comme étant potentiellement créatifs en raison de la présence de nombreux équipements culturels, de commerces et de cafés 
vecteurs d'une vie nocturne importante (KQ Ückendorf dans la vieille ville de Gelsenkirchen, $\mathrm{KQ}$ Wisenviertel à proximité de la gare de Witten). Ces projets s'apparentent davantage à de larges opérations de revitalisation urbaine dans lesquelles la culture et la créativité jouent un rôle au même titre que les actions menées en faveur de l'habitat, du développement commercial et du cadre de vie.

51 Pour assurer la réussite économique de ces quartiers créatifs, artistes, responsables des équipements culturels, écoles, laboratoires de recherche, aménageurs et promoteurs immobiliers sont invités à travailler ensemble et à mettre en place une stratégie de développement. A partir de 2010, les initiatives se multiplient. Des associations regroupant ces différents acteurs se créent. Des centres de la création (KQ Wanne à Herne), des incubateurs (incubateur pour la culture contemporaine au KQ Oberhausen Mitte) et des espaces de coworking (KQ Wiesenviertel de Witten) apparaissent pour assurer le développement du secteur. Le tissu d'équipements culturels se densifie. Les festivals chargés de faire connaître les créations locales (festival de musique Ruhrpuls organisé dans le KQ Viktoria à Bochum) se multiplient. Néanmoins, les retombées économiques demeurent à ce jour encore très limitées. Ainsi, en dépit de divers dispositifs d'accompagnement (zone franche, incubateur, aide financière du Land...), le Game Factory Ruhr n'accueille au bout de cinq années d'activité qu'une petite quinzaine de TPE. Les créateurs initialement implantés dans le quartier créatif de l'Unionviertel, à proximité directe du Dortmunder U, sont progressivement chassés par la spéculation immobilière encouragée par le projet urbain associé à l'arrivée du nouveau centre d'art contemporain dans l'ancienne brasserie locale. Si la jeunesse des projets rend le bilan difficile à établir, les premiers éléments d'observation nous montrent néanmoins des retombées territoriales globalement mitigées.

Conscient que ce type d'industrie repose principalement sur des phénomènes de réputation et souhaitant développer la créativité locale, le Centre européen pour l'économie créative a lancé dès sa création un magazine culturel numérique, le LABKULTUR.TV, qui constitue à la fois un outil de communication sur les dynamiques créatives locales et une plate-forme de réflexion européenne sur les logiques de développement de ces industries. Des partenariats sont donc établis avec le Forum d'Avignon, un réseau interactif constitué de représentants des secteurs de l'art, de la culture, de la politique, des sciences et des industries créatives, ou au sein de l'European Creative Business Network (ECBN). L'objectif du Centre européen pour l'économie créative est d'assurer la conversion économique de la Ruhr par le développement des industries créatives. Un enjeu très (peut-être trop) ambitieux... En effet, si l'économie culturelle et créative représente à l'échelle de la Ruhr 10000 entreprises et 86000 salariés et a connu une croissance de $14,5 \%$ entre 2005 et 2008, des voix commencent à s'élever au sein de l'Association régionale de la Ruhr et des instances politiques du Land de Rhénanie $\mathrm{du}$ Nord-Westphalie pour souligner le caractère particulièrement capitalistique de ces activités qui ne remplaceront jamais les emplois perdus dans l'industrie lourde.

\section{Conclusion}

La création d'équipements culturels dans la vallée de l'Emscher est essentiellement liée au lancement dans les années 1980 d'une exposition internationale d'architecture largement soutenue par le Land de Rhénanie du Nord-Westphalie. Implantés sur d'anciennes friches industrielles, les équipements culturels ouverts dans le cadre de 
l'exposition internationale - une vingtaine au total - ont pour ambition de renverser l'image dépréciée de ce bassin minier en crise. Pour ce faire, les aménageurs ont fait appel à des architectes de renom qui ont pris le soin de conserver les principales caractéristiques patrimoniales du futur équipement culturel qui s'inscrit dans le cadre de vastes opérations de régénération urbaine intégrant à la fois des questions relatives au logement, aux transports, mais aussi à l'implantation d'espaces publics de qualité, d'activités économiques et commerciales. Si ces aménagements contribuent à recréer les centralités perdues de ces anciens "phares» de l'industrie minière allemande (Soyez, 1999), ils sont réalisés au détriment des centres-villes traditionnels qui ne disposent pas des mêmes qualités urbaines entraînant de véritables discontinuités territoriales et paysagères. Ces équipements culturels ont néanmoins le mérite de renverser l'image interne et externe de la vallée de l'Emscher. En effet, la stratégie de développement économique du territoire s'appuie désormais en partie sur son identité industrielle à la fois reconnue par les pouvoirs publics et les habitants, mais aussi sur un développement touristique de plus en plus important et largement soutenu par ce vaste réseau d'équipements culturels reliés par la Route de la culture industrielle.

$\mathrm{Si}$, sur un plan strictement urbanistique et d'image territoriale, les nouveaux équipements culturels de la vallée de l'Emscher tiennent leurs promesses, qu'en est-il de leurs retombées en matière économique et sociale ? Les différents exemples retenus dans le cadre de cette étude montrent l'image d'équipements culturels marqués par une fréquentation extrêmement aléatoire, chroniquement déficitaires et contraints de rechercher des financements extérieurs de plus en plus diversifiés pour survivre. En dehors de l'économie touristique, les équipements culturels n'ont que très peu d'effet d'entraînement. L'implantation d'entreprises, de nouveaux commerces et de surfaces de bureaux résulte davantage de vastes opérations de régénération urbaine que de la seule présence de l'équipement culturel. En matière sociale, le bilan n'est pas meilleur. Marqués par une forte inertie de leurs publics principalement composés de catégories socio-professionnelles aisées et de groupes scolaires, les équipements culturels ne sont pas véritablement des vecteurs de démocratisation culturelle. Ils ne sont pas non plus de gros pourvoyeurs d'emplois à l'échelle locale, même s'ils participent par le biais de leurs programmes de médiation à l'éducation des jeunes publics. D'un point de vue immobilier, les équipements culturels entraînent souvent une dynamique de revalorisation des prix du foncier, voire même un processus de gentrification lorsque ceux-ci s'inscrivent dans le cadre d'un projet urbain plus large.

Si les équipements culturels implantés dans la vallée de l'Emscher ont eu des retombées territoriales globalement limitées, ils ont néanmoins largement participé à la construction de la Ruhr en tant que métropole. Les projets d'équipements culturels développés dans le cadre des différents programmes urbains lancés depuis les années 1980, ont permis aux acteurs du territoire - villes, intercommunalité et Land - de se rapprocher et de coopérer. Les programmes mis en place dans les années 2000 sont désormais envisagés à l'échelle métropolitaine. La candidature du territoire au titre de Capitale européenne de la culture pour l'année 2010 en est l'illustration. En effet, si la ville d'Essen a porté le projet Ruhr 2010, son nom représente à lui seul les 53 communes d'une vaste métropole qui cherche à oublier son passé de conurbation industrielle en crise. Or, comment rendre cette dynamique culturelle viable sur le long terme et affirmer le statut de métropole de la Ruhr? Plusieurs solutions sont alors envisagées, de l'organisation d'événements pour continuer à assurer la visibilité internationale des 
équipements culturels comme la Capitale européenne de la culture en 2010 à la mise en place d'une stratégie métropolitaine de soutien aux industries créatives. Or ces différentes activités sont particulièrement capitalistiques alors que les impacts économiques et sociaux demeurent encore incertains. Leur financement sur le long terme se pose donc alors que de nombreuses villes de la Ruhr se trouvent dans une situation très délicate de surendettement. La question d'un financement privé de plus en plus conséquent des équipements culturels et des entreprises du secteur créatif est posée.

\section{BIBLIOGRAPHIE}

ANDRES L., AMBROSINO C. (2008), « Régénération culturelle et mutabilité urbaine : un regard franco-britannique », in LERICHE F., DAVIET S., SIBERTIN-BLANC M., ZULIANI J-M., L'économie culturelle et ses territoires, Toulouse, Presses Universitaires du Mirail, coll. Villes et Territoires, pp. 305-316.

BAILONI M. (2014), « La reconversion des territoires industriels par la culture dans les villes britanniques : un modèle en crise? ", Belgeo, 1.

BALLE C., POULOT D. (2004), Musées en Europe, une mutation inachevée, Paris, La Documentation Française.

BARBIER K. (2002), L'impact culturel des friches industrielles, Lille, Mémoire de DEA.

BAUDELLE G., KRAUSS G. (2014), "The governance model of two French national museums of fine arts relocated in the province: Centre Pompidou Metz and Louvre-Lens", Belgeo, 1.

BAYART D., BENGHOZI P-J. (1993), Le tournant commercial des musées en France et à l'étranger. Paris, La Documentation Française.

BIANCHINI F., DAWSON J., EVANS R. (1992), « Flagship projects in urban regeneration”, in HEALEY P., DAVOUDI S. \& TAVSANOGLU S. (eds.), Rebuilding the city; property-led urban regeneration, London, E \& FN Spon.

BIANCHINI F., PARKINSON M. (dir.) (1993), Cultural Policy and Urban Regeneration. The West European Experience, Manchester and New York, Manchester University Press.

BOELSUMS R. (2012), "Living next to a flagship development. A literature review on the spatial and socio-economic benefits that flagship developments can generate for adjacent residential neighbourhoods", Regional Studies Association, February 2012.

BOLDT K.W., GELHAR M. (2008), Das Ruhrgebiet. Landschaft-Industrie-Kultur, Darmstadt, WBG.

BONNEVILLE M. (2004), «Les ambiguïtés du renouvellement urbain en France », Les Annales de la Recherche Urbaine, 97, Paris, PUCA, pp. 7-15.

BOQUET M. (2014), « L'impact touristique des nouveaux musées : analyse des relations entre l'environnement urbain et la spatialisation de l'impact à travers les exemples du Centre Pompidou-Metz et du Louvre-Lens ", Belgeo, 1.

BRONNY H.M., JANSEN N., WETTERAU B. (2002), Das Ruhrgebiet. Landeskundliche Betrachtung des Strukturwandels einer europäischen Region, Allemagne, Kommunalverband. 
BURBANK M.J., ANDRANOVICH G., HEYING C.H. (2005), “Mega-events, urban development and public policy", Review of policy research, 19 3, pp. 179-202.

CAMAGNI R., MAILLAT D., MATTEACCIOLI A. (dir.) (2004), Ressources naturelles et culturelles, milieux et développement local, Neuchâtel, EDES.

CHANTELOT S. (2006), « Une géographie du capital humain créatif en France », Les annales de la recherche urbaine, 101, pp. 147-153.

COMMISSION EUROPEENNE (2012), Promouvoir les secteurs de la culture et de la création pour favoriser la croissance de l'emploi dans l'Union européenne, Communication de la Commission au Parlement européen, au Conseil, au Comité économique et social européen et au Comité des régions, Bruxelles.

COMUNIAN R., MOULD O. (2014), “The weakest link: Creative industries, flagship cultural projects and regeneration", City, Culture and Society, 5, 2, pp. 65-74.

DOUCET B. (2009), “Global flagships, local impacts”, Urban Design and Planning, 162, pp. 101-107.

EISINGER P. (2000), “The politics of bread and circuses: building the city for the visitor class", Urban Affairs Review, 35, pp. 316-333.

ESSEX S., CHALKLEY B. (2004), “Mega-events as a strategy for urban regeneration”, Dialoghi Internazionali - Città nel Mondo, 5, pp. 18-29.

FAGNONI E., (2009), «Culture décentralisée et innovation urbaine. Metz et le Centre Pompidou », in LEMASSON J.-P., VIOLIER P. (dir.), Destinations et territoires, 1, Coprésence à l'œuvre, Québec, Téoros/Presses de l'Université du Québec, pp. 206-219.

FAUST H. (1999), « Das Ruhrgebiet - Erneuerung einer europäischen Industrieregion : Impulse für den Strukturwandel durch die Internationale Bauausstellung Emscher Park », Europa Regional, 7, 2, pp. 10-18.

FLORIDA R. (2002), The rise of the creative class, New York, Basic Books.

GANSER K. (1996), Die Internationale Bauaustellung Emscher Park : Struckturpolitik für Industrieregionen, Bochumer AG, 58, pp. 189-196.

GANSER K. (2001), “IBA Emscher Park in der Rückschau. Beitrag zur nachhaltigen Entwicklung?", Petermanns Geographische Mitteilungen, 145, 5, pp.18-25.

GENTGES E. (2011), Les reconversions industrielles. La question du développement durable, Liège, Mémoire de recherche.

GETZ D. (2007), Event studies: theory, research and policy for planned events, London, Routledge.

GOMEZ M., GONZALEZ S. (2001), "A reply to Beatriz Plaza's 'the Guggenheim-Bilbao Museum Effect”, International Journal of Urban and Regional Research, 25, 4, pp. 898-900.

GRAS P. (2007), « Cardiff veut lier développement et grands événements », Géocarrefour, 82, 3.

GRAVARI-BARBAS M., VIOLIER P. (dir.) (2003), Lieux de culture, culture des lieux, Rennes, PUR.

GRAVARI-BARBAS M. (2009), « "Marques d'architecte", "Marque de musée", l'architecture médiatique en tant qu'outil de positionnement touristique urbain ", in LEMASSON J.-P., VIOLIER P. (dir.), Destinations et territoires : coprésence à l'œuvre, Québec, Téoros/Presses de l'Université du Québec, pp. 190-205.

GRESILLON B. (2008), « Villes et création artistique : pour une autre approche de la géographie culturelle », Annales de géographie, juin 2008, pp. 179-199. 
GRODACH C. (2010), “Beyond Bilbao: Rethinking Flagship Cultural Development and Planning in Three California Cities”, Journal of Planning Education and Research, 29, pp. 353-366.

GUEIT J. (2005), La culture, moteur de réparation et d'une nouvelle image des villes industrielles : le Louvre-Lens, Lille, Mémoire de Master.

HALBERT L. (2010), L'avantage métropolitain, Paris, PUF.

HALL P. (1998), Cities in Civilization, New York, Pantheon Books.

HOLZ J.-M. (1988), La Ruhr, crise, reconversion et dynamique régionale, Metz, Thèse de doctorat d'Etat ès lettres.

INGALLINA P., PARK J. (2005), « Les nouveaux enjeux de l'attractivité urbaine », Urbanisme, 344, Paris, Publications d'architecture et d'urbanisme, pp. 66-68.

JENCKS C. (2005), The iconic building: the power of enigma, New York, Rizzoli.

JOLY N. (2001), Les territoires renouvelés de l'après-charbon, Lille, Thèse de doctorat.

KUNZMANN K.R. (1996), “Schöne weisse Arbeitselefenten in Zukunfsplatz. Topos”, Landscape European Magazine, np.

KURTH D., SCHEUVENS R., ZLONICKY P. (1999), Laboratorium Emscher Park, Städtebauliches Kolloquium zur Zukunft des Ruhrgebietes, Dortmund, Informationskreis f. Raumplanung.

LANDRY C., GREENE L., MATARASSO F., BIANCHINI F. (1996), The art of regeneration: urban renewal through cultural activity, Southend-on-Sea, Bournes Green, Commedia.

LANDRY C. (2000), The creative city - a toolkit for urban Innovators, London, Earthscan Publications.

LAUDERBACH M. (2012), "Effective governance to develop creative quarters: three cases from Germany", Quaestiones Geographicae, Poznan, Bogucki Wydawnictwo Naukowe, 31, 4, pp. 77-86.

LEFEVRE P. (2000), «L'art du paysage à Emscher Park », Les Annales de la recherche urbaine, 85, Paris, PUCA, pp. 190-195.

LEVINE M.V. (2004), « La classe créative et la prospérité urbaine : mythes et réalités », Conférence présentée à Montréal : Villes Régions Monde, INRS-Urbanisation, Culture et Société.

LEVY J. (1995), « Paris métropolitains. Réseaux et territoires de l'espace parisien », in LERESCHE J.P., JOYE D., BASSAND M., Métropolisations. Interdépendances mondiales et implications lémaniques, Genève, Georg, pp. 57-73.

LOFTMAN P., NEVIN B. (1995), "Prestige projects and urban regeneration in the 1980s and 1990s: a review of benefits and limitations", Planning Practice and Research, 10, pp. 299-316.

LUCCHINI F. (1997), « Les équipements culturels au service de la population des villes », Cybergeo : European Journal of Geography, Dossiers, Colloque "Les problèmes culturels des grandes villes", 8-11 décembre 1997, p. 352.

LUCCHINI F. (2012), La fabrique des lieux : réapproprier des lieux par la culture, Colloque international pluridisciplinaire "De la friche industrielle au lieu culturel", Rouen, 14 juin 2012, pp. 9-21.

LUNDVALL B.-Å., JOHNSON B. (1994), “The learning economy", Journal of Industry Studies, 1-2, pp. 23-42.

LUSSO B. (2008), «Les politiques culturelles à Roubaix, à la croisée de l'urbain et du social », Culture et gouvernance locale, 1, 1, pp. 79-91. 
LUSSO B. (2009), « Les musées, un outil efficace de régénération urbaine ? Les exemples de Mons (Belgique), Essen (Allemagne) et Manchester (Royaume-Uni) », Cybergéo, Espace, Société, Territoire, p. 436.

LUSSO B. (2010), « Culture et régénération urbaine : les exemples de la vallée de l’Emscher et du Grand Manchester ", Métropoles, 8.

LUSSO B. (2011), « Les dynamiques territoriales du secteur de l'image en mouvement dans les aires métropolitaines de Lille, de Lyon et de Marseille », Lille, Thèse de doctorat.

LUSSO B. (2013), « Patrimonialisation et greffes culturelles sur des friches issues de l'industrie minière », EchoGéo, 26.

MARKUSEN A. (2006), "Urban development and the politics of a creative class: evidence from the study of artists", Environment and planning A, 38-10, pp. 1921-1940.

MASBOUNGI A. (dir.). (2000), « L'IBA Emscher Park, un anti-modèle », Projet urbain, p. 21. ORIGET DU CLUZEAU C., TOBELEM J-M. (2009), Culture, tourisme et développement : les voies d'un développement, Paris, L'Harmattan.

PASSERON J.-C. (2005), « S'entendre sur le concept de démocratisation », Problèmes économiques et sociaux, 910, pp. 32-36.

PFIRSCH T., REITEL B. (2014), « Editorial : les grands équipements culturels dans les espaces industriels en reconversion : de la requalification urbaine aux projets métropolitains ?», Belgeo, 1.

PROSSEK A., SCHNEIDER H., WESSEL H.A., WETTERAU B., WIKTORIN D. (dir) (2009), Atlas der Metropole Ruhr, Köln, Emons Verlag.

ROBERTSON M., FREW E. (2008), Events and festivals: current trends and issues, London, Routledge.

ROCHE M. (2006), “Sports, Mega-events, modernity and capitalist economies”, The sociological review, 54, 2, pp. 25-40.

RODRIGUEZ A., MARTÍNEZ E., GUENAGA G. (2001), “Uneven redevelopment: new urban policies and socio-spatial fragmentation in metropolitan Bilbao", European Urban and Regional Studies, 8 , pp. 161-178.

SCHNEIDER J.M. (1991), IBA Emscher Park. Zukunftswerkstatt für Industrieregionen, Köln, Rudolf Müller.

SCOTT A.-J. (2004), “Cultural-Products Industries and urban Economic Development: prospects for growth and market contestation in a global context", Urban Affairs Review, 39, 4, New York, SAGE, pp. 461-490.

SMITH A. (2012), Events and urban regeneration: the strategic use of events to revitalize cities, London, Routledge.

SMYTH H. (1994), Marketing the city: the role of flagship developments in urban regeneration, London, E \& Fn Spon.

SOYEZ D. (1999), « Le patrimoine industriel des régions d'industrialisation ancienne », Textes Géographiques Virtuels sur le Canada et l'Allemagne, http://www.v-g-t.de/francais/brd/module/m2/ u9.htm

TEMELOVÁ J. (2007), "Flagship developments and the physical upgrading of post-socialist inner city: the Golden Angle project in Prague”, Geografiska Annaler: Series B, Human Geography, 89, pp. 95-195. 
TREMBLAY R. (2006), « La qualité de vie dans les villes du savoir », Norois, 200, pp. 91-95.

TREMBLAY R., TREMBLAY D.G. (2010), La classe créative selon Richard Florida : un paradigme plausible ?, PUR, Rennes.

VIVANT E. (2006), « La classe créative existe-t-elle? », Les Annales de la recherche urbaine, 101, numéro spécial Economies, connaissances, territoires, pp. 155-161.

VOASE R. (1997), The Role of flagship cultural projects in urban regeneration, Managing Leisure, 2, 4, pp. 230-241.

WERQUIN T. (2008), L'impact des équipements et évènements culturels sur le développement économique local : entre fantasme et réalité. Actes du colloque « Arts et Territoires : vers une nouvelle économie culturelle?", Québec, 6 et 7 mai 2008, np.

WILKINSON S. (1992), “Towards a new city? A case study of image-improvement initiatives in Newcastle Upon Tyne”, in HEALEY P., DAVOUDI S. \& TAVSANOGLU S. (eds.), Rebuilding the city; property-led urban regeneration, London, Spon, pp. 174-211.

ZEPF M., ANDRES L. (dir.), (2011), Enjeux de la planification territoriale en Europe, Lausanne, Presses polytechniques et universitaires romandes, Collection espace en société.

\section{RÉSUMÉS}

D’un point de vue économique, social et environnemental, la vallée de l'Emscher est à la fin des années 1980 le secteur le plus sinistré de la Ruhr. Pour assurer la reconversion et renverser l'image négative du territoire, le Land de Rhénanie du Nord-Westphalie a notamment misé sur la culture en lançant une exposition internationale d'architecture. Créés sur d'anciennes friches industrielles, les équipements culturels ont développé une architecture iconique et se sont inscrits dans le cadre de vastes programmes de régénération urbaine. Toutefois, les retombées territoriales de ces nouveaux équipements culturels sont limitées. S'ils contribuent fortement à stimuler l'économie touristique régionale, ils demeurent financièrement déficitaires, ce qui pousse le Land de Rhénanie du Nord-Westphalie à diversifier leurs activités, notamment par le développement d'expositions temporaires, de festivals ou la mise en place d'une stratégie en direction des industries créatives.

From an economic, social and environmental point of view, the Emscher Valley was at the end of the 1980s the more sinister area of the Ruhr. To ensure conversion and improve the negative image of the territory, the Land of North Rhine-Westphalia has used launched an international architecture exhibition. Created on former industrial wastelands, cultural facilities have developed an iconic architecture within the framework of urban regeneration programs. However, the territorial impact of these new cultural facilities is limited. If they strongly contribute to boost regional tourism economy, they are structurally in deficit. The Land of North Rhine-Westphalia must diversify their activities with the development of temporary exhibitions, festivals or the launch of a strategy into the creative industries. 
INDEX

Mots-clés : équipements culturels, vieille région industrielle, régénération urbaine, économie culturelle, industries créatives

Keywords : cultural facility, old industrial area, urban regeneration, cultural economy, creative industries

\section{AUTEUR}

BRUNO LUSSO

Université Lille 1 - Laboratoire T.V.E.S, bruno.lusso@gmail.com 